\title{
Molecular investigation of genetic assimilation during the rapid adaptive radiations of East African cichlid fishes
}

\author{
Helen M. Gunter ${ }^{1,2^{*}}$ (D) | Ralf F. Schneider ${ }^{1,3^{*}}$ (D) | Immanuel Karner ${ }^{4}$ | \\ Christian Sturmbauer $^{4}$ (D) | Axel Meyer ${ }^{1,3,5}$ (D)
}

${ }^{1}$ Lehrstuhl für Zoologie und

Evolutionsbiologie, Department of Biology, University of Konstanz, Konstanz, Germany

${ }^{2}$ Zukunftskolleg, University of Konstanz,

Konstanz, Germany

${ }^{3}$ International Max Planck Research School for Organismal Biology, University of Konstanz, Konstanz, Germany

${ }^{4}$ Department of Zoology, University of Graz, Graz, Austria

${ }^{5}$ Radcliffe Institute for Advanced Study, Harvard University, Cambridge, MA, USA

\section{Correspondence}

Axel Meyer, Lehrstuhl für Zoologie und Evolutionsbiologie, Department of Biology, University of Konstanz, Konstanz, Germany. Email: axel.meyer@uni-konstanz.de

\section{Present address}

Helen M. Gunter, Edinburgh Genomics, University of Edinburgh, Ashworth Laboratories, Edinburgh, EH3 3JT, United Kingdom.

\section{Funding information}

Deutsche Forschungsgemeinschaft; Zukunftskolleg at the University of Konstanz; The University of Konstanz; Austrian Science Fund grant; International Max Planck Research School

\begin{abstract}
Adaptive radiations are characterized by adaptive diversification intertwined with rapid speciation within a lineage resulting in many ecologically specialized, phenotypically diverse species. It has been proposed that adaptive radiations can originate from ancestral lineages with pronounced phenotypic plasticity in adaptive traits, facilitating ecologically driven phenotypic diversification that is ultimately fixed through genetic assimilation of gene regulatory regions. This study aimed to investigate how phenotypic plasticity is reflected in gene expression patterns in the trophic apparatus of several lineages of East African cichlid fishes, and whether the observed patterns support genetic assimilation. This investigation used a split brood experimental design to compare adaptive plasticity in species from within and outside of adaptive radiations. The plastic response was induced in the crushing pharyngeal jaws through feeding individuals either a hard or soft diet. We find that nonradiating, basal lineages show higher levels of adaptive morphological plasticity than the derived, radiated lineages, suggesting that these differences have become partially genetically fixed during the formation of the adaptive radiations. Two candidate genes that may have undergone genetic assimilation, gif and alas1, were identified, in addition to alterations in the wiring of LPJ patterning networks. Taken together, our results suggest that genetic assimilation may have dampened the inducibility of plasticity related genes during the adaptive radiations of East African cichlids, flattening the reaction norms and canalizing their feeding phenotypes, driving adaptation to progressively more narrow ecological niches.
\end{abstract}

\section{KEYWORDS}

adaptive radiation, alas1, Astatoreochromis alluaudi, Astatotilapia burtoni, Cichlidae, flexible stem, gif, Haplochromis ishmaeli, pharyngeal jaw apparatus, phenotypic plasticity, Pseudocrenilabrus

multicolor, Tropheus moorii

\section{1 | INTRODUCTION}

Adaptive radiations often involve either the colonization of novel habitats or movement into vacant niche space that can arise after the eradication of existing diversity (Losos, 2010). The formation of

*co-first authorship such species flocks is characterized by an explosive increase in species number within a lineage, typically via specialization to a multitude of ecological niches (Schluter, 2000). While intense competition between species for limited resources often results in extinction (competitive displacement) (Sepkoski, 1996), lineages that undergo adaptive radiation respond, more often, through diversification via the de novo occupation of vacant ecological niches (ecological 
opportunity) (Schluter, 2000). Thus, identifying the unique genetic, epigenetic, morphological and ecological features of lineages that undergo adaptive radiations provides a first step in understanding the mechanisms that promote speciation (Brawand et al., 2014; Henning \& Meyer, 2014). In spite of the potential value of stem lineage characterization, few studies on adaptive radiation have focused on this aspect (Schluter, 2000; West-Eberhard, 2003).

It has been hypothesized that adaptive radiation may be initiated by lineages that have recently evolved key innovations (Simpson 1953), or display high levels of variation that is either genetic (Hedrick, 2013), plastic (Pfennig et al., 2010) or a combination of the two (Gomez-Mestre \& Jovani, 2013). In spite of this, current research into the basis of adaptive radiations predominantly focuses on ultimate causes, namely natural selection of standing genetic variation (Mayr, 1961; Schluter, 2000), with fewer studies focusing on proximate causes such as phenotypic plasticity and developmental flexibility in stem lineages (West-Eberhard, 2003). Both proximate and ultimate experimental approaches are useful in explaining evolutionary phenomena; however, it is increasingly clear that proximate and ultimate causes can interact to drive evolution, so studies that incorporate both have higher explanatory power (Laland, Odling-Smee, Hoppitt, \& Uller, 2013; Laland, Sterelny, Odling-Smee, Hoppitt, \& Uller, 2011). Thus, studies that incorporate factors such as phenotypic plasticity have the potential to deepen our understanding of adaptive radiation, as it is likely to play an underappreciated role. Indeed, many of the model adaptive radiations contain at least some "basal" phenotypic plasticity in key ecological traits (West-Eberhard, 2003), such as sticklebacks (Lucek, Sivasundar, \& Seehausen, 2014; Morris et al., 2014; Oke et al., 2016; Wund, Baker, Clancy, Golub, \& Fosterk, 2008; Wund, Valena, Wood, \& Baker, 2012), Anolis lizards (Kolbe \& Losos, 2005; Losos et al., 2000), Darwin's finches (Tebbich, Sterelny, \& Teschke, 2010), Hawaiian spiders (Yim, Brewer, Miller, \& Gillespie, 2014) and cichlid fishes (Bouton, Witte, \& Van Alphen, 2002; Meyer, 1987b; Muschick, Barluenga, Salzburger, \& Meyer, 2011; Stauffer \& van Snick Gray 2004; Wimberger, 1991). Moreover, a recent study even linked phenotypic plasticity to a major evolutionary transition - the origin of tetrapods (Standen, Du, \& Larsson, 2014). In spite of this, phenotypic plasticity is frequently not considered both in discussions of mechanisms leading to adaptive radiations and in evolution more generally (Pigliucci, 2007; West-Eberhard, 2003).

During the initial phases of adaptive radiations, phenotypic plasticity can provide an inherent competitive advantage during the colonization of new or heterogeneous habitats (Baldwin, 1896; Ghalambor, McKay, Carroll, \& Reznick, 2007; Lande, 2009; Morris et al., 2014; Richards, Bossdorf, Muth, Gurevitch, \& Pigliucci, 2006). Phenotypically plastic species, which are commonly generalists (Van Tienderen, 1997), are also more likely to meet their resource requirements during the colonization of novel environments (Baldwin, 1896). Additionally, phenotypic plasticity enhances trait variability within stem lineages by generating multiple phenotypes from single genotypes (West-Eberhard, 2003) by exaggerating trait differences between lineages through ecological displacement (Schluter, 1994), and through increasing the accumulation of standing genetic variation (Gomez-Mestre \& Jovani, 2013). Together, this would be expected to enhance the probability of rapid and parallel colonization of open niches, as is observed in adaptive radiations (Pfennig et al., 2010). Although phenotypic plasticity is likely to contribute to lineage diversification, the degree to which it contributes to this process remains unresolved (Hendry, 2016) and is an ongoing topic of debate (De Jong, 2005; Schneider \& Meyer, 2017).

The concept of genetic assimilation shows how novel phenotypes (phenotypic diversification) can originate from phenotypic plasticity (Crispo, 2007; Pfennig et al., 2010; Schneider \& Meyer, 2017). How might phenotypic plasticity contribute to the origin of new phenotypes (phenotypic diversification) and potentially to speciation (lineage splitting)? Genetic assimilation can contribute to speciation when phenotypic plasticity generates alternative phenotypes (WestEberhard, 1989, 2003) that are later fixed through reproductive isolation. In this scenario, when specific plastic phenotypes are consistently induced over many generations through sustained exposure to stable environmental stimuli, natural selection acts only on these phenotypes and the associated quantitative genetic variation, while alternative phenotypes remain non-induced and are thus "released" from directional or stabilizing effects of selection (Waddington, 1953, 1961; West-Eberhard, 1989). Subsequently, the environmental sensitivity of these alternative phenotypes declines when natural selection acts either positively (DeWitt, Robinson, \& Wilson, 2000) or negatively (Ghalambor et al., 2015) to the direction of plastic change, or through neutral processes (Masel, King, \& Maughan, 2006). Cases that involve a reduction in phenotypic plasticity are termed genetic assimilation, while any shift in reaction norm after exposure to a novel environmental stimulus can be termed genetic accommodation (Crispo, 2007). For the purposes of this manuscript, we use the term genetic accommodation for changes that cannot be classed as genetic assimilation.

Genetic assimilation was first demonstrated empirically in fruit flies by Conrad H. Waddington (1953), and a putative molecular mechanism was proposed much later (Rutherford \& Lindquist, 1998; Waddington, 1961). Although genetic assimilation has been demonstrated by common garden experiments (Carroll, Dingle, \& Klassen, 1997; Carroll, Klassen, \& Dingle, 1998; Chapman, Galis, \& Shinn, 2000; Cook \& Johnson, 1968; Ghalambor et al., 2007; Parsons \& Robinson, 2006; Reznick \& Ghalambor, 2005; Robinson \& Wilson, 1996), the loci that may underlie this have rarely been studied in natural populations (Ledón-Rettig, Pfennig, Chunco, \& Dworkin, 2014; Parsons et al., 2016). Therefore, their importance in natural evolutionary processes is difficult to evaluate. The genetic variation that contributes to genetic assimilation can arise through accumulation of standing genetic variation in the stem lineage (Jarosz \& Lindquist, 2010), through epigenetic alterations (Sollars et al., 2003; Zhao et al., 2005) or through de novo mutation. Then, selection (Snell-Rood, Van Dyken, Cruickshank, Wade, \& Moczek, 2010) or drift (Masel et al., 2006) influences the degree of plasticity of ecologically relevant traits in subsequent generations. For example, genetically assimilated loci in a derived, specialist lineage may show a lower magnitude expression response to a plastic stimulus (i.e., a 
shallower reaction norm) in comparison with that of the stem lineage. In the case of adaptive radiations, the restriction of plasticity would make particular trait values increasingly heritable thus potentially allowing natural selection to further fine-tune the phenotypes to the specific niche requirements. Thus, less plastic specialist lineages would be expected to outcompete more plastic, generalist lineages when they inhabit a stable environment.

To test the role of phenotypic plasticity and possible subsequent genetic assimilation in adaptive radiations, we selected East African cichlid fishes as our models. As one of the most species-rich families of vertebrates, and with exceptionally large and diverse adaptive radiations that arose independently in East Africa and the New World, cichlid fishes represent a particularly suitable model for investigating speciation and adaptive radiation (Albertson, Markert, Danley, \& Kocher, 1999; Brawand et al., 2014; Friedman et al., 2013; Genner et al., 2007; Salzburger, 2009; Schluter, 2000; Seehausen, 2006; Seehausen et al., 2008; Turner, 2007; Wagner et al., 2013). The adaptive radiations of the East African lakes are particularly impressive, with around 500 species in Lake Victoria alone, most of which evolved in less than 100,000 years (Genner et al., 2007; Meyer, Kocher, Basasibwaki, \& Wilson, 1990; Salzburger, Mack, Verheyen, \& Meyer, 2005; Stager \& Johnson, 2008). Phenotypic plasticity may well have contributed to these dramatic radiations, as it plays a role in generating alternative feeding phenotypes that finetune the exploitation of specialized niches (Machado-Schiaffino, Henning, \& Meyer, 2014; Meyer, 1987b, 1990a,b; Muschick et al., 2011; Stauffer \& van Snick Gray, 2004; Van Dooren, Van Goor, \& Van Putten, 2010; Wimberger, 1991). Moreover, phenotypic plasticity has been demonstrated in the feeding apparatus' of cichlid species from within (Bouton et al., 2002; Kerschbaumer, Postl, Koch, Wiedl, \& Sturmbauer, 2011; Machado-Schiaffino et al., 2014; Muschick et al., 2011) and outside of (Stauffer \& van Snick Gray, 2004; Wimberger, 1991) the cichlid adaptive radiations; however, until now, it was not compared in a single experiment.

Arguably the best-studied cichlid example of adaptive phenotypic plasticity is the pharyngeal jaw of Astatoreochromis alluaudi (Greenwood, 1965; Gunter et al., 2013; Hoogerhoud, 1986a,b; Huysseune, 1995; Huysseune, Sire, \& Meunier, 1994; Schneider, Xiong, Li, Meyer, \& Gunter, 2014; Smits, 1996; Smits, Witte, \& VanVeen, 1996). This species modulates the development of its pharyngeal jaws (a second pair of "crushing" jaws in the throat), in response to the robustness of the available diet. Ingesting a soft diet (SD; e.g., insect larvae) induces a slender "papilliform" jaw with numerous fine teeth, while a hard diet (HD; hard-shelled snails) induces a

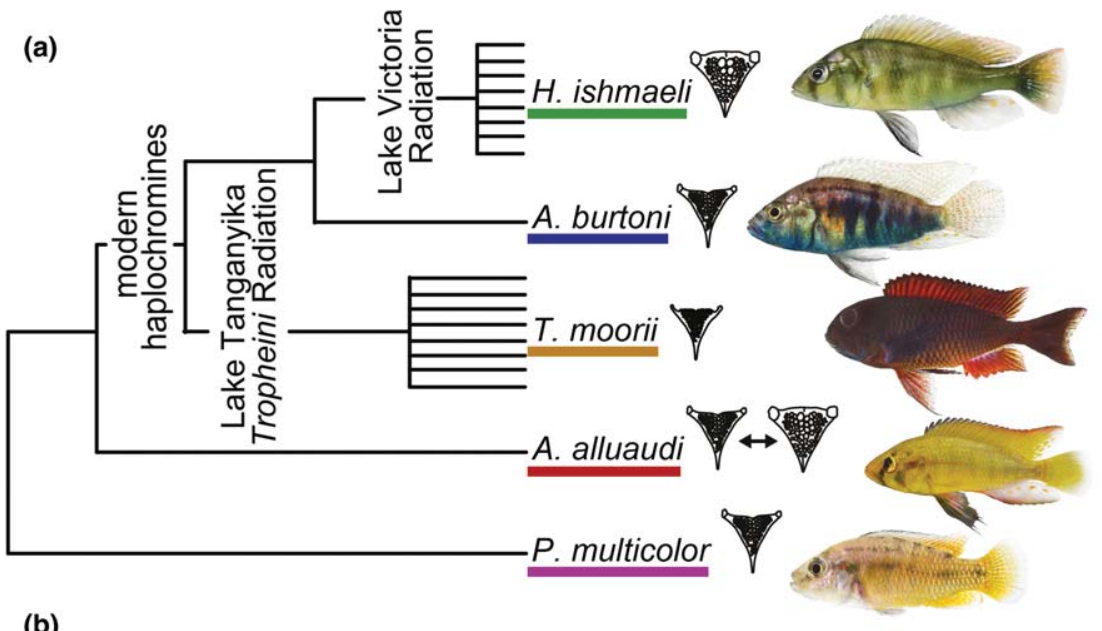

(b)
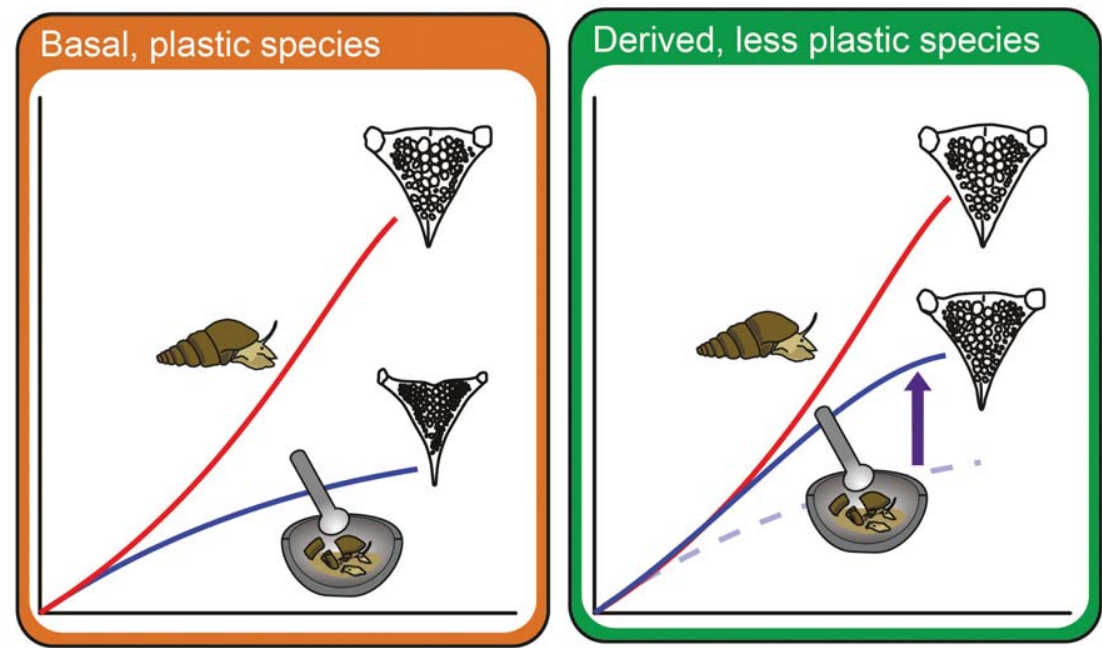

FIGURE 1 Evolutionary relationships and lower pharyngeal jaw (LPJ) morphology sketches of cichlid species included in this study. (a) Representatives of lineages basal to adaptive radiations include the riverine generalist species Astatoreochromis alluaudi, Pseudocrenilabrus multicolor and Astatotilapia burtoni. More "derived" species from adaptive radiations include Tropheus moorii, a specialist representative of the Lake Tanganyika Tropheini radiation, and Haplochromis ishmaeli, a specialist representative of the Lake Victoria radiation. (b) Hypothesis for the direction of change in morphology and gene expression under the assumption of genetic assimilation. Here, the baseline condition (soft diet) of more derived species should approach the induced condition (hard diet) for plastic species, and there should be overall a more limited degree of plasticity 
hypertrophied "molariform" jaw with larger, molar-like teeth, most notably in the Lower Pharyngeal Jaw (LPJ) (Figure 1a). Thus, the resulting adults were suggested to more efficiently exploit the two alternative diet niches and avoid competition with other more specialized species (Cosandey-Godin, Binning, \& Chapman, 2008; Greenwood, 1959, 1965; Hulsey, Hendrickson, \& de León, 2005; Slootweg, Malek, \& Mccullough, 1994). In addition to numerous morphological studies, recent molecular investigations of adaptive plasticity in the pharyngeal jaws of A. alluaudi have shed light on its transcriptional underpinnings (Gunter et al., 2013; Schneider et al., 2014). Specifically, this research has identified a number of genes that display dynamic patterns of expression throughout development of molariform and papilliform jaws. These genes are putatively involved in the development of bone, tooth and muscle, as well as the response to mechanical strain, the putative plasticity stimulus (Gunter et al., 2013; Schneider et al., 2014).

The goal of this research was to investigate whether dietinduced adaptive phenotypic plasticity is likely to have contributed to adaptive radiations in East African cichlid fishes. To examine this, we tested whether (i) proxies of the founders of the adaptive radiation are highly plastic in an adaptive trait (LPJ molariform/papilliform morphologies) and (ii) whether plasticity at that trait is lost during the adaptive radiation because of genetic assimilation. Our taxa included two specialist species from two independent adaptive radiations in Lakes Victoria (Haplochromis ishmaeli) and Tanganyika (Tropheus moorii) and two riverine generalist species branching more basally - that are phylogenetically and geographically outside these adaptive radiations. These include A. alluaudi, and Astatotilapia burtoni, plus a member of a more basally branching ancestral lineage, Pseudocrenilabrus multicolor (Figure 1a; for phylogenetic relationships see Salzburger et al., 2005 and Brawand et al. 2014). The relatively basal, nonradiating riverine lineages are hypothesized to fill a similar ecological niche to the common ancestor(s) of the radiations that colonized the lakes (Clabaut, Bunje, Salzburger, \& Meyer, 2007; Genner et al., 2007; Meyer, 1993; Stager \& Johnson, 2008) and the two others occupy more specialized trophic niches (Greenwood, 1965; Yamakoa, 1983). Diet manipulation experiments allowed us to test whether the cichlid adaptive radiations are likely to have evolved from a phenotypically plastic ancestral lineage that specialized and radiated to fill an array of narrow ecological (trophic) niches. The LPJs of diet-manipulated fish were then examined for morphology and gene expression through qRT-PCR of mechanically responsive genes identified by our previous study, with the goal of testing for genetic assimilation and its putative transcriptional basis.

\section{2 | MATERIALS AND METHODS}

\section{1 | Cichlid diet experiments}

Five cichlid species were selected for diet manipulation experiments based on previous evidence of diet-induced phenotypic plasticity, phylogenetic position and the diets of natural populations (Figure 1a). These included two rather basal species: Astatoreochromis alluaudi and Pseudocrenilabrus multicolor. A. alluaudi is known to have a highly plastic pharyngeal jaw that becomes larger and more robust in response to a hard diet such as hard-shelled snails. It is geographically widespread with populations that inhabit both riverine and lacustrine environments, exploiting both insects and algae (soft diet) and molluscs (hard diet) (Cosandey-Godin et al., 2008; Greenwood, 1965; Slootweg et al., 1994; Witte, 1981). We used a laboratory population that was obtained from the Mwanza Gulf in Lake Victoria in 1984 and, since then, was kept at Leiden University and the University of Konstanz and has been used in numerous plasticity experiments (Gunter et al., 2013; Hoogerhoud, 1986b; Huysseune, 1995; Huysseune et al., 1994; Schneider et al., 2014; Smits, 1996; Smits et al., 1996). As a second out-group, we used the generalist riverine species $P$. multicolor, which branches basally to A. alluaudi (Binning \& Chapman, 2008; Salzburger et al., 2005) and has no previous record of plasticity in the pharyngeal jaws, albeit its gills (which are adjacent to the LPJ) are known to be plastic (Chapman et al., 2000; Crispo \& Chapman, 2008, 2010). Additionally, more phylogenetically derived species were included: the riverine species Astatotilapia burtoni, a generalist that feeds mostly on insects, but also plants and algae (Salzburger et al., 2005; Sturmbauer, Hainz, Baric, Verheyen, \& Salzburger, 2003; Theis, Ronco, Indermaur, Salzburger, \& Egger, 2014), Haplochromis ishmaeli, a snail-cracking specialist endemic to Lake Victoria (Greenwood, 1965; Hoogerhoud, 1986a; Slootweg, 1987), and Tropheus moorii, an algae browsing specialist that is endemic to Lake Tanganyika (Sturmbauer, Mark, \& Dallinger, 1992; Sturmbauer \& Meyer, 1992; Sturmbauer et al., 2003; Yamakoa, 1983). All species had been bred in captivity for multiple generations and were obtained from laboratory stocks (A. alluaudi [Witte, Leiden] A. burtoni [Hoffman, Austin] and T. moorii [Sturmbauer, Graz]) or the aquarium trade $(H$. ishmaeli and $P$. multicolor). These species are likely to display similar patterns of development, as this is the case for cichlid species separated by greater phylogenetic distance (Holden \& Bruton, 1994).

Diet manipulation experiments were conducted using methods modified from Gunter et al. (2013) and Meyer (1990a,b). Briefly, 1-2 clutches of $\sim 6$-month-old fish from each species (all bred at University of Konstanz) were raised separately then split into two groups. Each group was raised in a single tank and fed diets that differed only in the mechanical strain required for processing, but not in their nutritional content. One group ingested a hard diet (HD) composed of hard-shelled snails that had to be cracked with their pharyngeal jaws, and the second group ingested a soft diet (SD) of an equivalent quantity of crushed snails. Both were also fed ad libitum with commercial flake food each morning. The experiment was terminated after approximately 8 months, a period of time known to induce significant plasticity in A. alluaudi (Schneider et al., 2014). Our previous work showed that plasticity-driven size and shape differences develop gradually (Schneider et al., 2014), with statistically significant adaptive divergence after $\sim 5$ months of treatment. For all species, HD individuals were observed to take the snails into their mouths during the experimental period ( $\mathrm{H}$. Gunter pers. obs.). The standard length for each individual was noted, and the lower pharyngeal jaws (LPJ) were 
dissected and stored in RNA-later at $-20^{\circ} \mathrm{C}$ for further processing. All statistical analyses were performed with R (RC-Team 2012).

\section{2 | Analytical workflow}

Three main datasets were analysed in this study: LPJ linear morphometric measurements, LPJ geometric morphometric measurements and LPJ candidate gene expression measurements (details below). Each of the three raw data sets was processed, either for betweenspecies comparisons or for within species diet group comparisons (HD vs. SD). For all six data subsets, the following analyses were performed: (i) a principal component analysis (PCA), in which all principal components (PCs) are considered until their cumulative explained variance exceeds $95 \%$ of the total variance; (ii) an analysis of variance (ANOVA) or multivariate ANOVA (MANOVA), testing for differences in PCs by species or diet (selection was depended on the number of considered PCs); (iii) pairwise comparisons among species or between diet groups, performed separately for each considered PC (when species were compared, Tukey-HSD post hoc correction was performed). Additional data set-specific analyses were performed as outlined below. Finally, we integrated gene expression and linear morphometric measurements using multiple linear regressions with species-specific PCA components as dependent and gene expression variables as independent variables.

\section{3 | Linear morphometric analyses}

LPJs were cleaned and photographed, and linear and geometric morphometric measurements were made according to Gunter et al. (2013). Final sample sizes for linear morphometric measurements were $(n=S D, H D)$ : A. alluaudi $n=9,11$; A. burtoni $n=15,11$; H. ishmaeli $n=8,9$; P. multicolor $n=5$, 9; and T. moorii $n=7,6$. Briefly, linear measurements included length, width and depth of the LPJ, width of the muscle attachment horns, various tooth measurements and LPJ weight (Fig. S1). For species comparisons, data were first standardized through dividing morphometric measurements by standard lengths and then centring each variable (through subtracting the mean value from each data point). For diet group comparisons, first a linear regression was fitted separately for each species and measurement, using the morphometric variable as a dependent length and standard length as an independent variable to obtain size-corrected residuals. These fit residuals were then scaled and centred, that is, the mean for each gene was subtracted from individual values and was then used for within-species diet group comparisons. In addition to the aforementioned PCA and downstream analyses, pairwise comparisons of diets were conducted on all measurement variables using $t$ tests for unequal variances and false discovery rate (FDR) post hoc $p$-value corrections.

\subsection{Geometric morphometric analyses}

The geometric morphometrics analyses used two landmarks and 14 semi-landmarks that outlined the LPJs (Fig. S1D). Standardization for species comparisons was carried out by aligning all species' landmarks together using the $\mathrm{R}$ geomorph package procrustes fit (Adams \& Otárola-Castillo, 2013). For diet group comparisons, LPJ landmarks were aligned for each species separately. As the LPJ is considered a bilaterally symmetrical structure, variation between the left and right side was removed: landmark coordinates from the left side of the LPJ were mirrored onto the right side along the LPJs' anterior-posterior axes and average coordinates for each landmark pair per LPJ were calculated. Then, left-side-averaged landmarks were mirrored back to the right side. No allometric effect of standard length on shape variation was detected within species. Final sample sizes were $(n=S D, H D)$ : A. alluaudi $n=9,11 ;$ A. burtoni $n=11,9 ; H$. ishmaeli $n=8$, 9; P. multicolor $n=5,9$; and T. moorii $n=6,6$.

\section{$2.5 \mid$ Gene expression analyses}

RNA was extracted from the LPJs using a modified protocol, suitable for extractions from bones (Gunter et al., 2013). Thirteen candidate genes were selected from our previous publications (Gunter et al., 2013; Schneider et al., 2014), based on having putative functions in driving plastic development in the LPJs. These fall into different categories and are likely to influence different aspects of the development of plasticity in the LPJ, including the immediate response to mechanical strain, bone modelling and remodelling, and the development of larger teeth and muscles. Specifically, these include the "immediate early" genes $c$-fos and rgs2; genes that influence the osteoblast lineage runx $2 b$ and osx; extracellular matrix genes col12 and col6; calcium pathway genes ryr and srl, and the muscle-related genes tpm4 and des. Moreover, we included gif, alas1 and c1q-like, genes with putative roles in the inflammatory response, which were observed to be repressed or induced in response to a strain-inducing diet in A. alluaudi (Gunter et al., 2013; Schneider et al., 2014). These genes showed a dynamic expression pattern during plastic development (Schneider et al., 2014), and the analysis of gene expression in the LPJs at $\sim 8$ months represents a snapshot of this pattern.

RNA extraction and gene expression analyses were performed only for A. alluaudi, A. burtoni and $H$. ishmaeli as morphometric measurements indicated no significant diet-induced divergence in $P$. multicolor and T. moorii, and we did not expect to see a difference in expression in these jaws (see Results section). Synthesis of cDNA and qRT-PCR was performed according to Schneider et al. (2014). Briefly, after confirming the quality of total extracted RNA (Bioanalyzer RIN values above 6.0 and A260:280 > 1.8), cDNA was synthesized using Superscript III, primed by oligo dTs. Primers of candidate genes were designed using sequence from A. alluaudi RNA-seq contigs (Table S1; Gunter et al., 2013), and their efficiencies were optimized for A. alluaudi, A. burtoni and $H$. ishmaeli through analyses of standard curves. Specifically, each primer pair was tested on a dilution series generated from pooled cDNAs from each species. In the cases where $E<1.85$ or $>2.15$, new primers were designed, based on genome traces for A. burtoni (osx, rgs2 and gif) (Brawand et al., 2014), or alternative regions of the A. alluaudi gene sequence for H. ishmaeli (actinR, twinfilin, osx, runx2 and gif). Final sample sizes 
were $(n=S D, H D)$ : A. alluaudi $n=9,11 ;$ A. burtoni $n=11,9 ; H$. ishmaeli $n=8$, 9 .

qRT-PCR was used to analyse candidate gene expression in two technical replicates for each individual, where expression levels were averaged (Gunter et al., 2013). For among-species comparisons, gene expression levels were calculated using the formula: norm. $\exp _{g i}=\frac{E_{g s p}-C_{g i}}{\left(E_{a c t ~ s p}{ }^{-C a c t ~} i+E_{\text {twin sp }}-C_{\text {twini }}\right) / 2}$, which enabled between-species comparisons. Parameters are individual (i), mean $C_{t}$ values $\left(C_{t}\right)$ and its species' $(s p)$ and gene's $(g)$ respective efficiency value (E). Values were then normalized by dividing them by the mean absolute expression values of the two housekeeping genes (act and twin). Although our e-values were calculated using best practice methods, any biases in their calculation would more strongly affect the species comparisons than the between diet, within species comparisons. Across the three species, gene expression was then scaled and centred, that is, the mean for each gene was subtracted from individual values. For diet group comparisons, we calculated standardized and normalized gene expression levels according to reference gene expression levels following Gunter et al. (2013). These gene expression values were then scaled and centred species-wise.

In addition to the aforementioned analyses, diet-induced differences in candidate gene expression were analysed using pairwise $t$ tests (for unequal variances). To correct for multiple testing, false discovery rate corrections were applied to all $p$-values for each species. Two-way ANOVAs on the gene expression data set were conducted (one per gene) using "gene expression" as the dependent variable and "diet group" and "species" as factors. To determine which species' reaction norm differs from which, the interaction of the two factors was also included and all ANOVAs were performed as pairwise comparisons, that is, each including only two of the three species. Notably, as gene expression was standardized gene-wise, gene effects are not informative so we focus our interpretation on the interaction term. To explore gene co-expression patterns, hierarchical clustering analyses were performed for each species (Haas et al., 2013). Finally, linear discriminant function analyses (IDFA) were conducted for $\mathrm{H}$. ishmaeli, $\mathrm{A}$. burtoni and $\mathrm{A}$. alluaudi to predict species and diet group memberships, respectively, using gene expression data (using the Ida() function from the R "MASS" package). Accuracy and leave-one-out (LOO) accuracy was calculated using the same dataset that was used to calculate the predictor to estimate predictor quality.

Reported effect sizes across analyses represent Cohen's $d$ for ANOVAs and $t$ tests, and $\eta^{2}$ for MANOVAs. The number of asterisks in plots indicates varying levels of significance $\left({ }^{*} .05>p \geq .01\right.$; ${ }^{* *} 0.01>p \geq .001 ;{ }^{* * *} .001>p$ ).

\subsection{Correction for sample-size effects by subsampling}

To determine the levels of plasticity among plastic species $(H$. ishmaeli, A. burtoni and A. alluaudi, see Results) and facilitate comparisons among the plastic species, species-wise PCAs were also performed on randomly subsampled datasets (to equalize sample sizes of $n=17$ ) for the linear morphometric, geometric and gene expression data sets. After each subsampling, MANOVAs were performed for each species on all considered PCs. This procedure was repeated 1,000 times for the linear morphometric data set (as sample sizes were more uneven) and 100 times for the other two data sets (which had more even sample sizes). Mean $p$-values, mean considered PCs and mean percentages of explained variation on PC1 are reported in Table S2.

\section{7 | Integrating gene expression and morphology}

To integrate gene expression measurements and morphometric measurements, multiple regression analyses were performed for $\mathrm{H}$. ishmaeli, A. burtoni and A. alluaudi separately. For each analysis, one principal component of the species-wise PCAs on linear morphometric measurements was used as dependent variable, while the scaled and centred gene expression values were used as independent variables. Model selection was then performed by removing and/or adding individual genes (i.e., independent variables) from/to the model (using stepAIC() functions from the R "MASS" package). The model with the lowest AIC value was considered as the final model. These regressions were individually performed for PCs1-3, and thus, covering the largest proportion of variation found in the linear morphometric datasets.

\section{3 | RESULTS}

\section{1 | Lower pharyngeal jaws of the focal species have distinct sizes, shapes and gene expression patterns}

After conducting controlled feeding trials on the five focal cichlid species, LPJs were dissected, enabling both linear and geometric morphometric analyses to be performed. Our among-species PCA analysis of linear morphometric measurements confirmed that each of the five investigated species has a unique LPJ morphology, putatively reflecting their ecological niches (Figures 1a, 2a, Fig. S2). The first PC, which was predominantly loaded with LPJ weight, explained $>95 \%$ of the total variation (Figure 2b; Fig. S2). An ANOVA indicated that the focal species differ significantly across PC1 ( $d f=4, F=56.5, p<.001$ ).

Similarly, our PCA of geometric morphometric measurements indicates moderate separation between the focal species, albeit to a lesser degree than the linear morphometric analyses (compare Figure 2a-c). Here, PC1 explains $51 \%$ of the variation, and PC2 explains $25 \%$ of the variation, with three further PCs required to explain $95 \%$ of the variation (Fig. S3). Jaw length and the shape of the posterior margin of the LPJ contribute most significantly to PC1 (Figure 2c,d), measures that are associated with relative molariformity (Gunter et al., 2013; Muschick et al., 2011). The different species clustered in a similar order to the linear morphometrics PCA, with Astatoreochromis alluaudi showing the most strongly molariform phenotype according to its position on PC1, and Tropheus moorii showing the most papilliform phenotype. A MANOVA confirms that species differ according to the considered PCs ( $d f=4$, Pillai $=1.6, F=10.2, p<.001)$. 

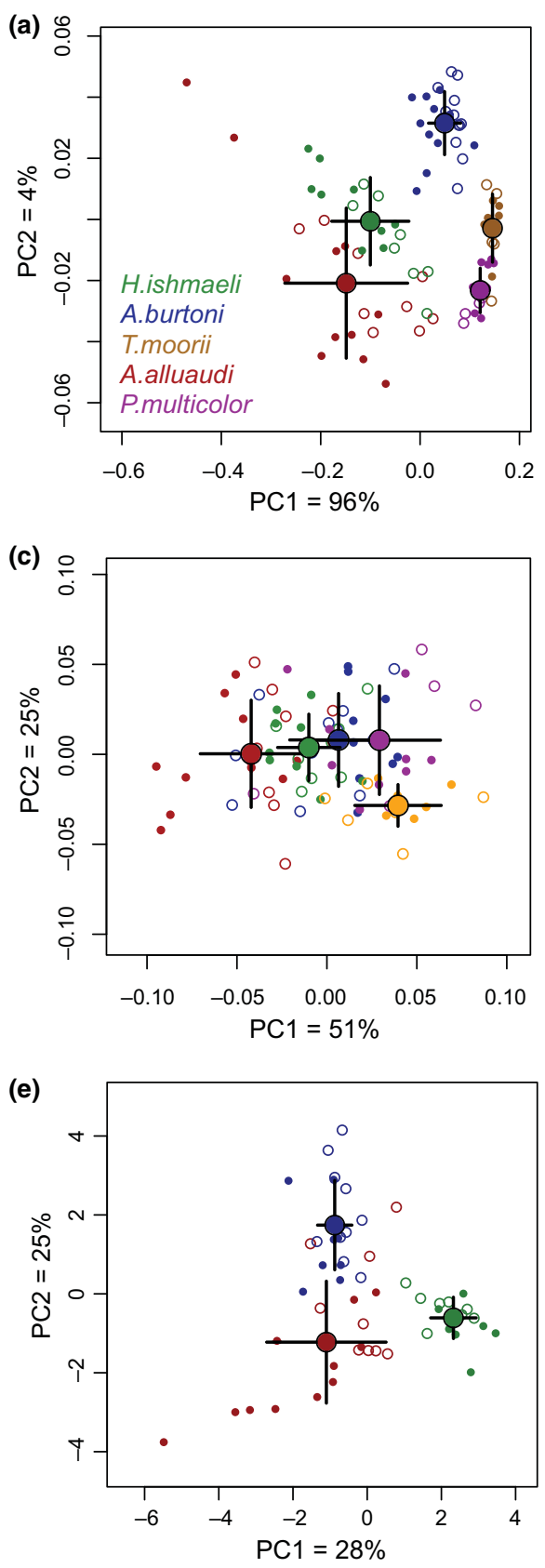

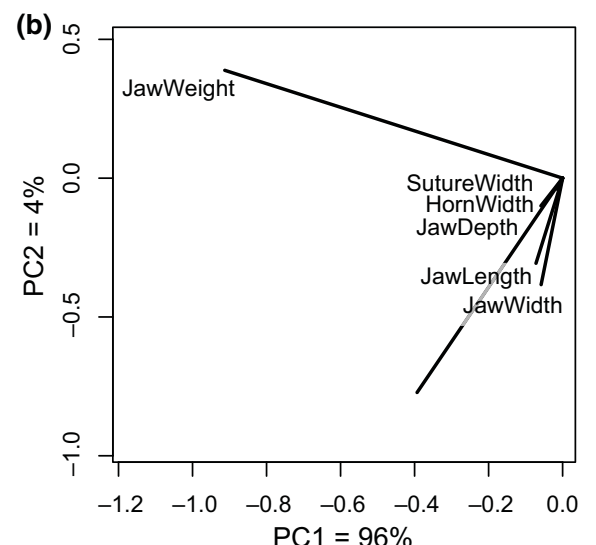

(d)
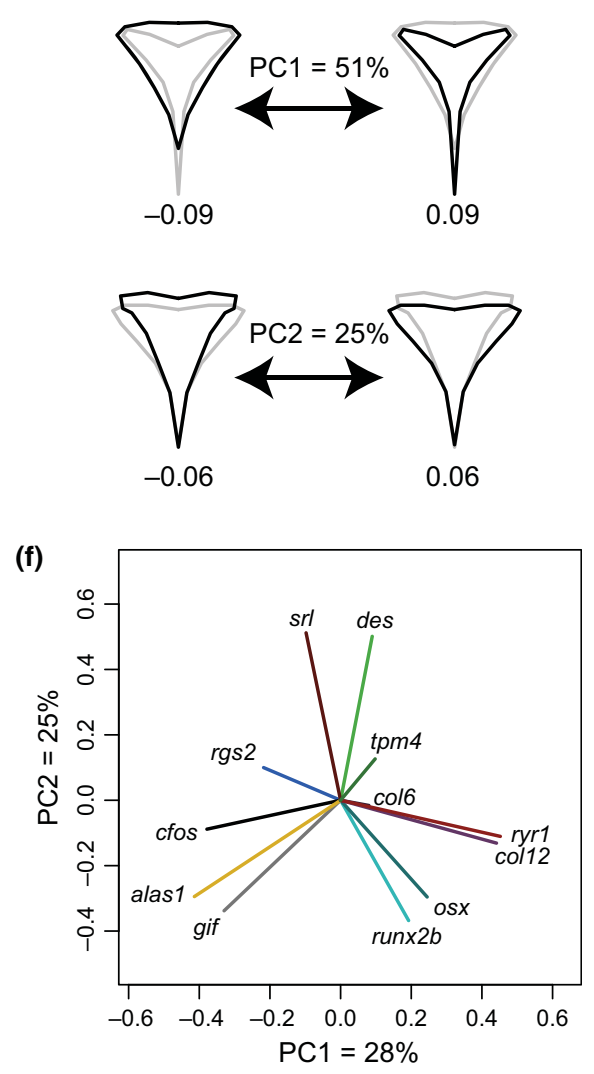

FIGURE 2 The lower pharyngeal jaws (LPJs) of five focal cichlid species occupy different morphospace, as per linear and geometric morphometric, and gene expression. (a, b) Principal component analyses were prepared for all linear LPJ measurements (absolute measurements divided by standard length), (c, d) geometric morphometric measurements and $(e, f)$ gene expression values (normalized to two housekeeping genes). (a) The five focal cichlid species can be separated based on PC1 and PC2. The cross-hairs show mean and standard deviations within each species. (b) PC loadings indicate that JawWeight is the most significant contributor to PC1. (c) The five focal cichlid species are moderately well separated on PC1 and PC2. The cross-hairs show mean and standard deviations within each species. (d) Black shapes indicate the most extreme shape of the respective axis end, while grey shapes indicates the extreme of the other end. (e) The three cichlid species used for gene expression analysis can be separated based on PC1 and PC2. The cross-hairs show mean and standard deviations within each species. (f) The 12 candidate genes contributed variably to PC1 and PC2
A PCA on candidate gene expression was performed for the three species to visualize transcriptional differences (Figure 2e,f, Fig. S4) that may underlie species-level differences in LPJ morphology (Figure 2a-d, Figs. S2 and S3). All species could be separated on the first two PCs, whereby Haplochromis ishmaeli was significantly separated from Astatotilapia burtoni and A. alluaudi on PC1, and A. burtoni was significantly separated from $\mathrm{H}$. ishmaeli and $\mathrm{A}$. alluaudi on PC2 (Figure 2e, Fig. S2). PC1 explains $28 \%$ of the variation between individuals, and PC2 explains a further $25 \%$. A further six PCs are required to explain $95 \%$ of the variation (Figs. S2 and S4). Different genes contribute to each of the PCs, with no single gene explaining a substantial portion of the variation (Figure 2e). Our MANOVA confirms species-specific gene expression $(d f=2$, Pillai $=1.8, F=147.4, p<.001$ ).

\subsection{Specialists of radiating lineages have shallower reaction norms than generalist, nonradiating lineages}

Similar to our previous experiments (Schneider et al., 2014), we confirmed that hard diet (HD) and soft diet (SD) treatments cause A. alluaudi to develop divergent LPJ morphologies after a feeding period of 8 months (Fig. S5; Table S3). For this species, we observed strong differences in all linear morphometric measurements examined (Fig. S5, Table S3). Interestingly, significant morphological plasticity was also detected in the more slender-jawed species, $A$. burtoni, where LPJ plasticity has not previously been demonstrated (Fig. S5; Table S3). For this species, the largest differences were observed in LPJ depth, largest and average tooth size $(p<.001)$ and jaw area $(p<.01)$. Morphological divergence was also demonstrated for $\mathrm{H}$. ishmaeli, albeit to a lesser 
extent than for A. alluaudi or A. burtoni (Fig. S5, Table S3). Significant differences were observed in LPJ area and depth, centroid size, weight, horn width and suture width $(p<.05)$. No significant differences were observed in T. moorii or Pseudocrenilabrus multicolor (Fig. S5, Table S3).

We conducted correlation-matrix-based PCAs of linear morphometric measurements for each species to explore patterns of diet-induced size variation (Figure 3). For A. alluaudi, PC1 explains $63 \%$ of the identified variation, and the two diet groups are clearly separable on this axis $(p<.001$, effect size Cohen's $d=2.61$ ) (Figure 3m-p). For PCAs generated for A. burtoni and $H$. ishmaeli, PC1 explains $59 \%$ and $45 \%$ of the total variation, respectively, with both species showing significant divergence between the two diet treatments $(p<.001 \&$ Cohen's $d=-2.16$ for A. burtoni and $p<.05 \&$ Cohen's $d=1.41$ for H. ishmaeli) (Figure $3 a-h)$. In contrast, only $39 \%$ and $34 \%$ of the variation is explained by PC1 in P. multicolor and T. moorii, respectively, and diet-induced divergence is not statistically significant (Cohen's $d=0.41$ and -0.23 for P. multicolor and T. moori, respectively, Figure 3i-l; q-t). MANOVA analyses on all considered PCs confirmed these patterns (Table S4). Subsampling of $A$. alluaudi and A. burtoni to match the sample size of $H$. ishmaeli confirmed that $A$. alluaudi is the most plastic species according to the linear morphometrics, closely followed by A. burtoni, while $H$. ishmaeli is considerably less (but still significantly) plastic (Table S5).

Further PCAs were conducted on geometric morphometric measurements for each species to explore patterns of diet-induced shape variation (Figs. S6 and S7). Hard and soft diets induced significant differences on at least one PC for A. alluaudi, A. burtoni and $H$. ishmaeli (PCs 2, 1 and 3, respectively; Fig. S7). No significant shape differences were observed for P. multicolor or T. moorii on any of the PCs that cumulatively explain $>95 \%$ of the variation (Figs. S6 and S7). Furthermore, MANOVA analyses suggest that although A. burtoni is the only species with significant diet group differences on PC1 (which carries the highest proportion of variation), significance using multiple PCs is higher in A. alluaudi and $H$. ishmaeli (Table S6), as also suggested by the higher effect sizes $\left(\eta^{2}=0.38,0.63\right.$ and 0.59 for $A$. burtoni, $H$. ishmaeli and A. alluaudi, respectively). Subsampling procedures further suggest that the attained level of significance of $A$. burtoni on PC1 may be the result of having a slightly higher sample size than $H$. ishmaeli and A. alluaudi (Table S2). Nonetheless, A. burtoni still shows a slightly higher level of significance than $\mathrm{H}$. ishmaeli.

\section{3 | Species-specific patterns of gene expression associated with adaptive plasticity in basal vs. derived lineages}

Expression of thirteen candidate genes was examined in the LPJs of $\mathrm{HD}$ and SD individuals for A. alluaudi, A. burtoni and $H$. ishmaeli, using
qRT-PCR (Fig. S8, Table S7). These were categorized according to functional annotations that include immediate early genes, heme genes, matrix genes, bone genes, muscle genes and calcium genes (Gunter et al., 2013). A few genes showed statistically significant differences in their expression between SD and HD groups. Among them were gif and alas1 for A. alluaudi, and osx and col6 for $\mathrm{H}$. ishmaeli. Moreover, an ANOVA predominantly supported these results, with significant interactions between species and diet for osx, alas1, col6 and col12 (Table 1), while marginal significance was detected for gif.

Species-wise PCA on gene expression revealed that in $\mathrm{H}$. ishmaeli, A. burtoni and A. alluaudi the scores of PC1 and PC3; PC1 and PC2; and PC4 were significantly different between diet groups, respectively ( $p<.05$, Fig. S9). Combined with significant MANOVAs using the considered PCs as dependent and diet as an independent variable $(d f=1,1,1$ Pillai $=0.85,0.75,0.79, F=5.5,4.0,6.58$, $p=.013, .018, .002, \eta^{2}=0.85,0.75,0.79$; for $H$. ishmaeli, A. burtoni and $A$. alluaudi, respectively), our data suggest that gene expression patterns differ between diet groups, although other factors may affect gene co-expression, as the scores of most heavily loaded PCs do not differ more strongly between diet groups. Our subsampling suggests that slightly higher significance levels in A. burtoni may be an artefact from slightly unbalanced sample sizes as subsampling reduces its significance level to lower than $\mathrm{A}$. alluaudi or $\mathrm{H}$. ishmaeli and effect sizes are similar among species (Table S2).

Linear discriminant function analysis was used to evaluate whether an individuals species classification could be correctly predicted based on its diet-induced gene expression patterns (Figure 4, Fig. S10). LD1 separated $H$. ishmaeli from A. alluaudi and A. burtoni, while LD2 separated all three species (Figure 4a). LOO cross-validation indicated a high accuracy, showing that all three species could be separated on the basis of gene expression (Figure $4 \mathrm{~b}$ ). Interestingly, genes relating to muscle structure and function (specifically calcium channels) on both LD 1 and LD 2 contributed most strongly to the predictors (ryr1, srl and tpm4), suggesting that they may dictate the observed species-level differences in the diet-induced plastic response (Fig. S10).

\section{4 | Gene expression relates to principle components of morphological variation}

We used multiple regression analysis to explore the relationship between gene expression and the first two principal components of linear morphological variation among A. alluaudi, A. burtoni and $H$. ishmaeli (Figure 5). Significance of selected multiple regression models was found for PC1 for A. alluaudi, PCs1 and 2 for A. burtoni, and PC2 for $\mathrm{H}$. ishmaeli. Among these, the PCs showed significant

FIGURE 3 Influence of diet on linear morphometric measurements in the lower pharyngeal jaws (LPJs) of cichlid species from within and outside adaptive radiations. Principal component analyses were produced for all measurements, and (a, e, i, $m, q)$ percentage of explained variance for each principal component, (b, f, j, n, r) variation on PC1 for soft diet (SD) and hard diet (HD) treatments, (c, g, k, o, s) variation at PC1 and PC2 and (d, h, l, p, t) loadings of each measurement on PC1-2 are displayed. Significant differentiation at PC1 was detected between HD and SD treatments for (b) H. ishmaeli $(p<.05)$, (e) A. burtoni $(p<.01)$, (m) A. alluaudi $(p<.001)$; however, significant differentiation was not detected for (i) T. moorii ( $p>$.05), or (q) P. multicolor ( $p>$.05) 
(a)

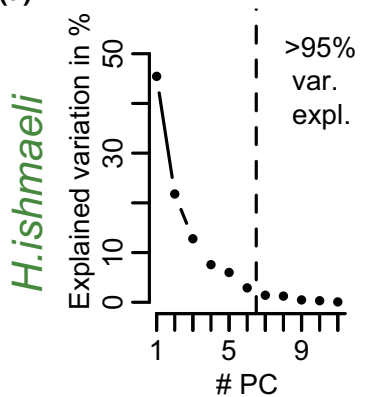

(e)

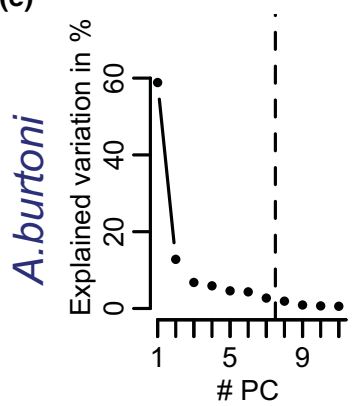

(i)

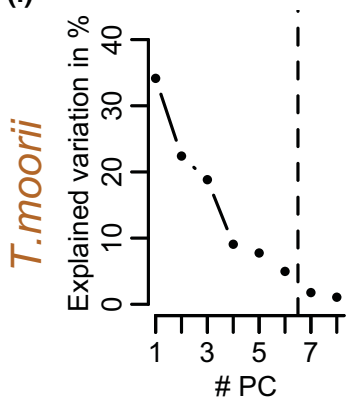

(m)

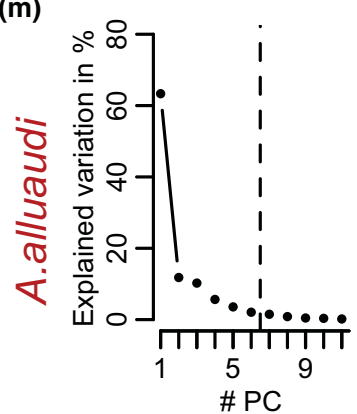

(q)

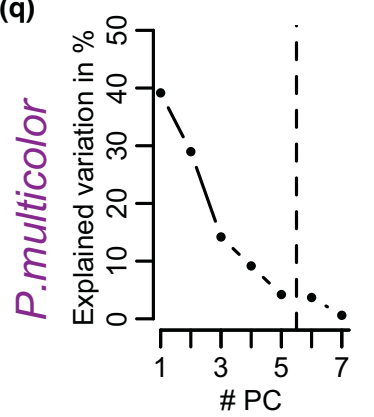

(b)

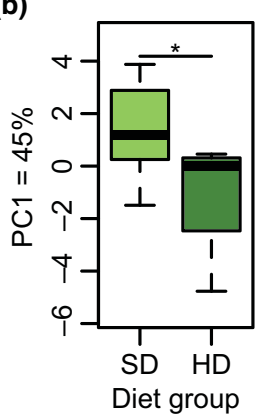

(f)

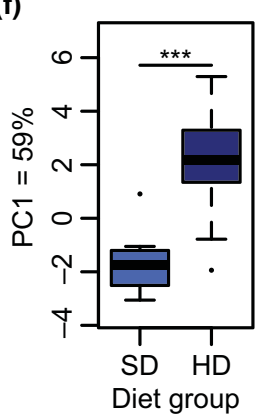

(j)

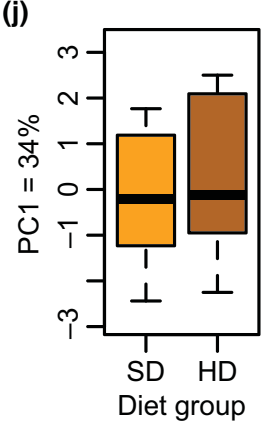

(n)

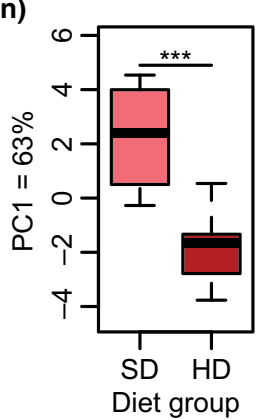

(r)

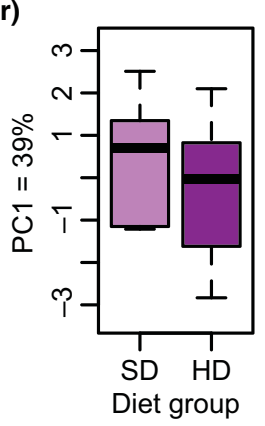

(c)

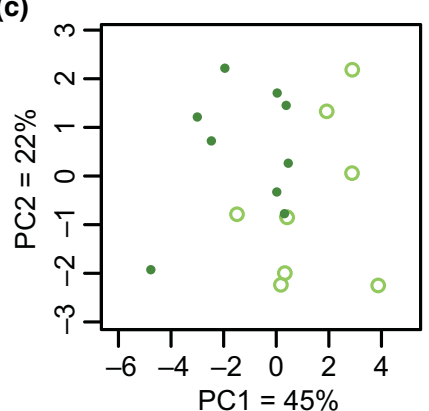

(g)

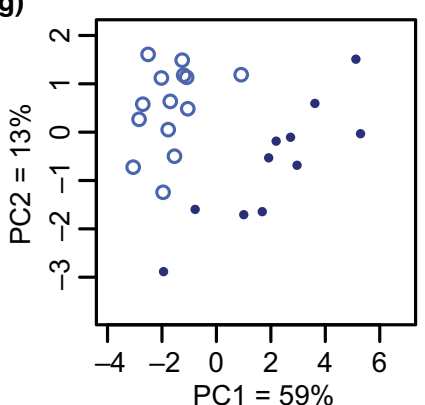

(k)

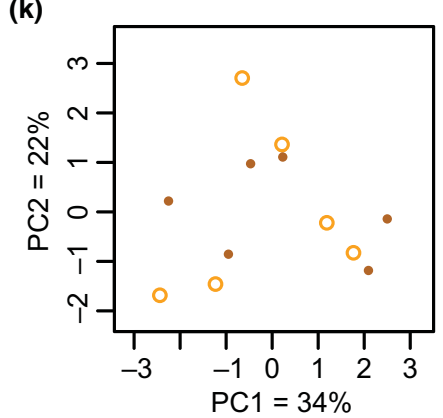

(o)

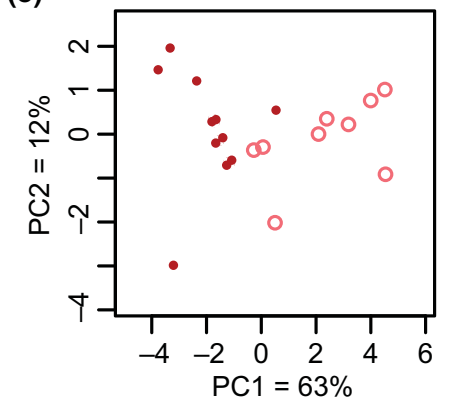

(s)

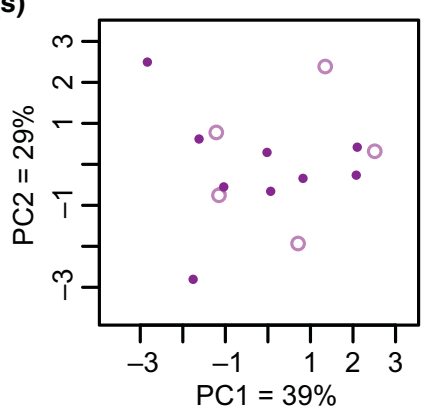

(d)

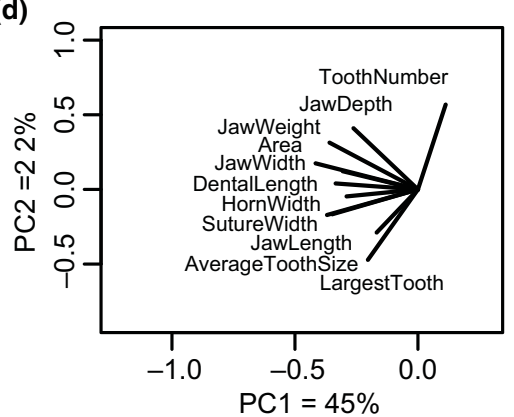

(h)

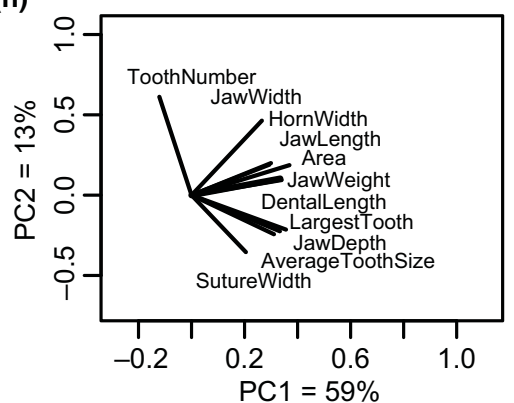

(I)

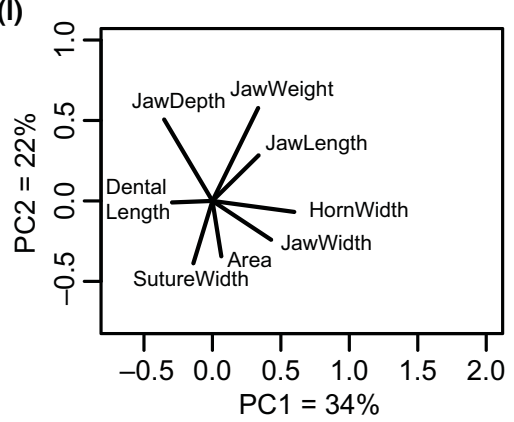

(p)

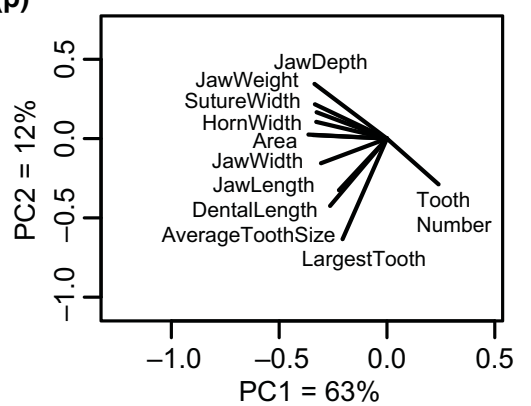

(t)

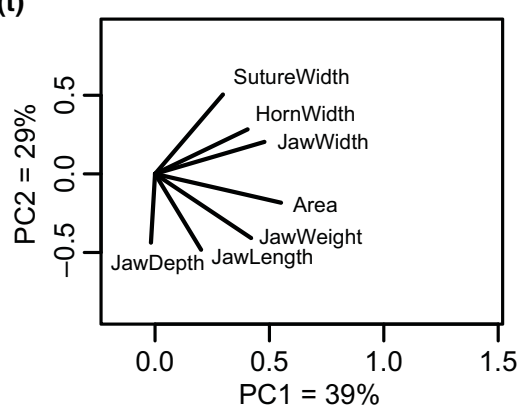


TABLE 1 Results from pair-wise ANOVAs using species as independent variable and gene expression as dependent variable

\begin{tabular}{lllllll} 
Gene & Species & \multicolumn{2}{l}{$\begin{array}{l}\text { Est. } \\
\text { comparison }\end{array}$} & $R^{2}$ & Est. & Est. \\
species & interact \\
\hline runx2b & alluaudi vs. burtoni & .277 & 0.095 & $0.528^{* *}$ & -0.010 \\
\hline osx & alluaudi vs. burtoni & .577 & -0.016 & $0.778^{* * *}$ & -0.237 \\
& alluaudi vs. ishmaeli & .172 & -0.016 & -0.062 & $0.247^{*}$ \\
& burtoni vs. ishmaeli & .529 & -0.254 & $-0.840^{* * *}$ & $0.484^{*}$ \\
\hline \multirow{2}{*}{ gif } & alluaudi vs. burtoni & .406 & $0.691^{* *}$ & 0.184 & 0.086 \\
& alluaudi vs. ishmaeli & .503 & $0.691^{* * *}$ & $0.438^{* *}$ & -0.369 \\
& burtoni vs. ishmaeli & .335 & $0.777^{* * *}$ & 0.254 & -0.455 \\
\hline \multirow{2}{*}{ alas1 } & alluaudi vs. burtoni & .457 & $0.430^{* *}$ & $0.343^{* *}$ & -0.014 \\
& alluaudi vs. ishmaeli & .482 & $0.430^{* * *}$ & $0.518^{* * *}$ & $-0.349^{*}$ \\
& burtoni vs. ishmaeli & .298 & $0.416^{* * *}$ & 0.175 & $-0.334^{*}$ \\
\hline \multirow{2}{*}{ col6 } & alluaudi vs. ishmaeli & .207 & -0.412 & $-0.934^{* *}$ & $0.864^{*}$ \\
& burtoni vs. ishmaeli & .191 & 0.163 & -0.266 & 0.288 \\
\hline \multirow{2}{*}{ col12 } & alluaudi vs. burtoni & .156 & 0.174 & $0.579^{* *}$ & -0.477 \\
& burtoni vs. ishmaeli & .565 & $-0.303^{*}$ & $-0.858^{* * *}$ & $0.573^{* *}$ \\
\hline \multirow{2}{*}{ ryr1 } & burtoni vs. ishmaeli & .142 & 0.079 & $0.341^{*}$ & -0.089 \\
\hline
\end{tabular}

Asterisks indicate the level of significance per model estimate.

diet-related differences for A. alluaudi and A. burtoni, but not $\mathrm{H}$. ishmaeli, which showed a nonsignificant trend of diet separation on PC2. For A. burtoni and A. alluaudi, we identified genes significantly contributing to the above morphological PCs, with each species showing a unique pattern of gene regulation. Notably, for A. alluaudi and A. burtoni, genes such as alas 1 and tmp4 are negatively and positively associated with the molariform phenotype, respectively (Figure 5c,e). Moreover, alas1 and gif show opposite patterns of association for these two species, despite belonging to similar functional categories. For $\mathrm{H}$. ishmaeli, alas1 is positively associated with variation on PC2, while tmp4 is negatively associated (Figure 5b). $c$-fos is positively associated with molariformity for A. alluaudi, A. burtoni and $\mathrm{H}$. ishmaeli, potentially reflecting its role in remodelling of bone and eruption of new (larger) teeth (Figure 5b,c,e).

\subsection{Candidates for genetic assimilation identified in derived lineages}

Our analysis of gene expression identified patterns that are suggestive of genetic assimilation or more specifically, a reduction in plasticity in derived lineages. First, gene expression patterns were compared to our model of genetic assimilation (Figures $1 \mathrm{~b}$ and $6 \mathrm{c}-$ d). Expression of gif and alas1 was consistent with our hypothesis of genetic assimilation, as both genes were significantly differentially expressed in A. alluaudi and A. burtoni, and their normalized expression levels in $H$. ishmaeli SD individuals were more similar to $H D$ than for the other two species (Figure 6A). That is, the reaction norm for these genes was shallower for $\mathrm{H}$. ishmaeli than for $\mathrm{A}$. alluaudi or A. burtoni. Conversely, osx and col6 showed expression patterns that represented a shift in the reaction norm in response to a novel environmental stimulus that differed from genetic assimilation (Figure 6b) and were categorized as genetic accommodation (Crispo, 2007). These were significantly differentially expressed in $\mathrm{H}$. ishmaeli; however, they were not differentially expressed in A. alluaudi or A. burtoni.

To investigate any putative alterations in gene expression networks in our focal species, we conducted hierarchical clustering analyses (Figure 6e-g). As was observed in previous studies (Gunter et al., 2013; Schneider et al., 2014), genes from similar functional categories were co-expressed in A. alluaudi. For example, discrete clusters were generally observed for the matrix genes (col6 and col12), the immediate early genes (c-fos and rgs2) and the bone genes (osx and runx2b). Also similar to Schneider et al. (2014), muscle-related genes (tpm4 and des) clustered with calcium-related genes (ryr1 and srl). The majority of genes analysed for A. burtoni and $\mathrm{H}$. ishmaeli displayed patterns of co-expression that were similar to A. alluaudi; however, they were not identical (Figure 6e-g). Notably for A. burtoni, matrix genes col6 and col12 were not coregulated, but rather col6 did not cluster with any other genes, while col12 clustered with the bone genes (Figure 6f). Additionally, for $\mathrm{H}$. ishmaeli the bone genes (osx and runx $2 b$ ) clustered within the muscle/calcium
FIGURE 4 Linear discriminant function analysis (IDFA) shows that gene expression can be used as a reliable predictor of species membership. Here, species was the dependent variable and gene expression (absolute, normalized values) was the independent variable matrix. (a) The three focal species could be clearly differentiated and (b) standard as well as leave-one-out (LOO) cross-validation support the reliability of predictors
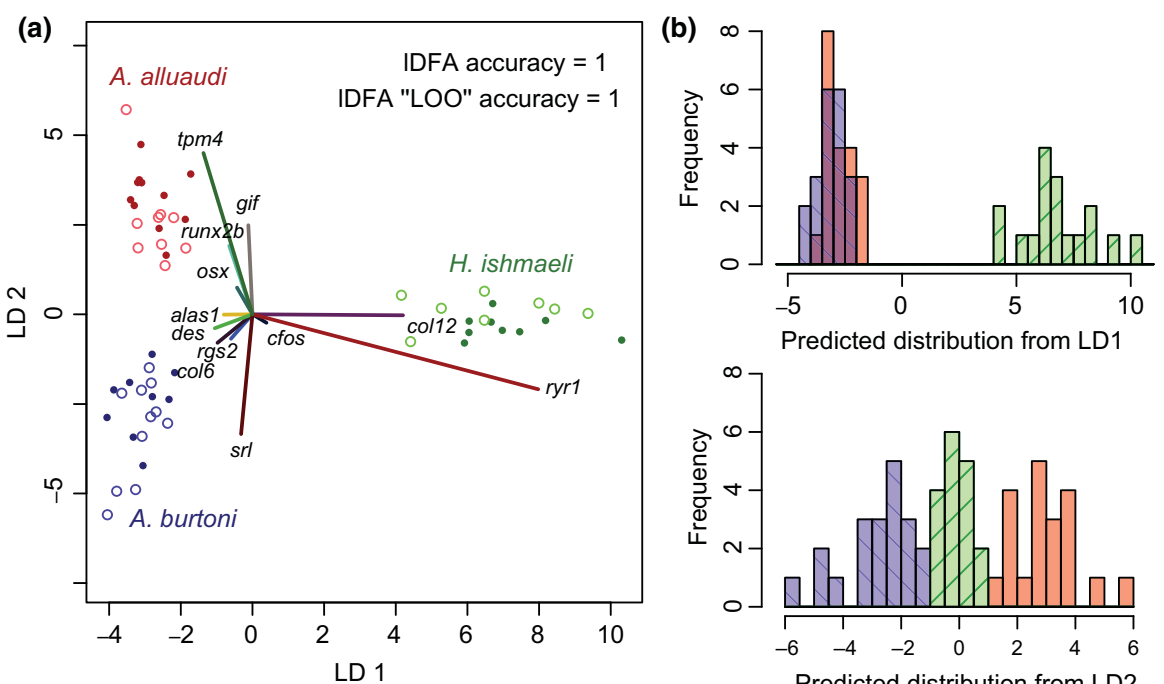

Predicted distribution from LD1

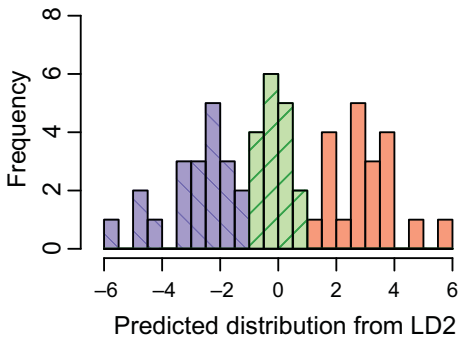



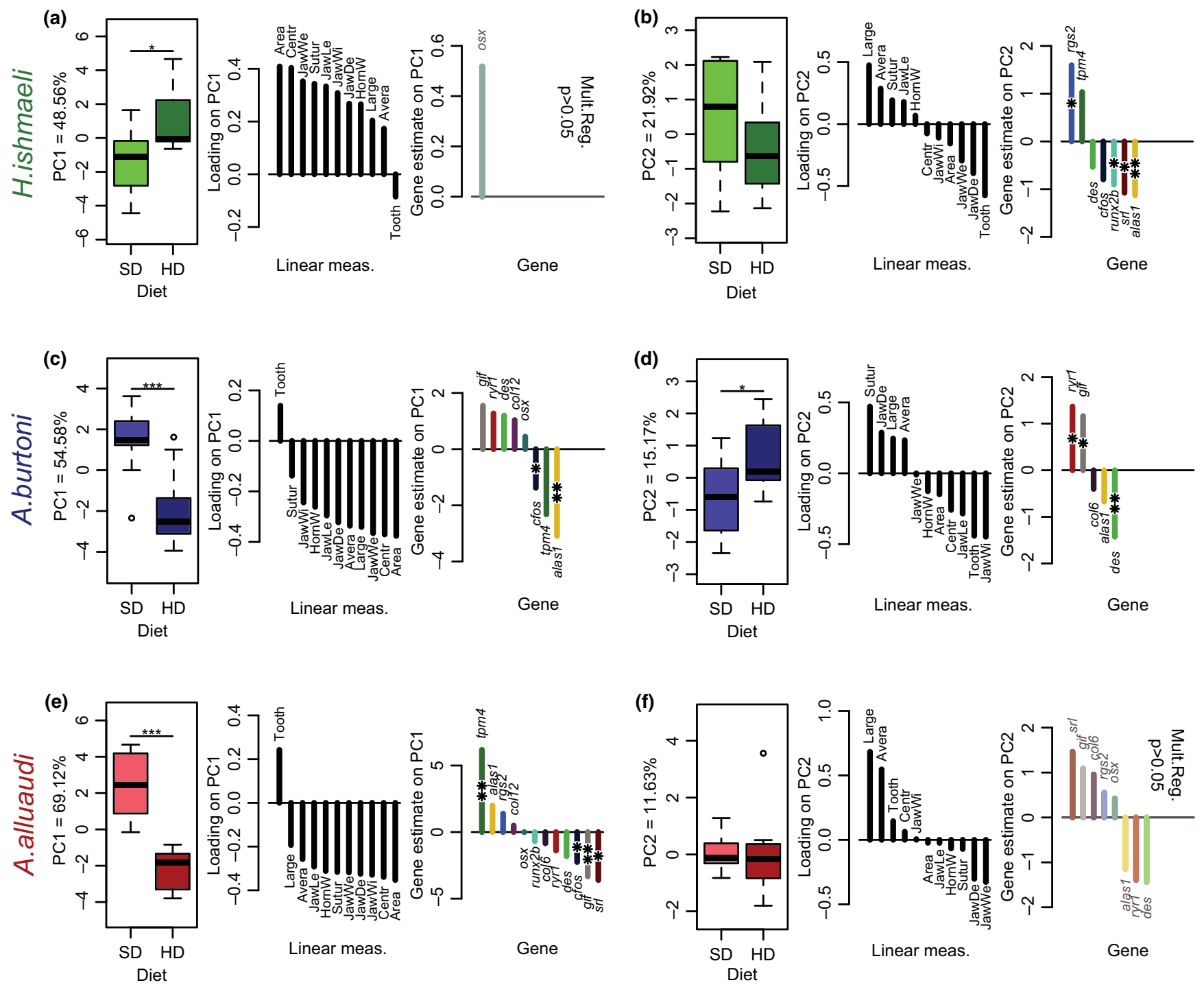

FIGURE 5 Linear regression shows that diet-induced morphology can be associated with gene expression. Here, the dependent variable was the PC1 scores of the PCA on linear morphometric measurements (Figure 2a) and gene expression was used as an independent matrix of variables. We report these for (a, c, e) PC1 and (b, d, f) PC2. Plots show (left) PC1 scores of linear morphometrics for the 3, (middle) the weighting of each morphometric variable on PC1 and (right) the contribution of each gene to the linear regression model. Area = dental area size, Avera $=$ average tooth size, Centr $=$ centroid size, HornW $=$ horn width, JawDe $=$ jaw depth, JawLe $=$ jaw length, JawWe $=$ jaw weight, JawWi $=$ jaw width, Large $=$ largest tooth size, Suture $=$ suture width, Tooth $=$ tooth number

genes, while the matrix genes (col6 and col12) formed a discrete cluster (Figure 6e). Together, these results suggest potential differences in the mechanical properties of the bone matrix and the proliferation of bone and tooth cells that comprise the LPJs of these species. Moreover, three genes identified as being substantial for our IDFA predictor (ryr1, srl and tpm4) were also consistently coexpressed for all three species according to our hierarchical cluster analysis (Figures 5 and $6 \mathrm{e}-\mathrm{g}$ ).

\section{4 | DISCUSSION}

Adaptive radiations have been the focus of many research investigations; however, relatively few studies have focused on whether particular characteristics of founding lineages predispose them to forming adaptive radiations (Schluter, 2000; West-Eberhard, 2003). One proposal is that such lineages might be especially phenotypically plastic (i.e., flexible stem lineages), which might facilitate the repeated colonization of different replicated environments, such as lakes, where one of a set of previously evolved alternative or stage-specific phenotypes is advantageously expressed (West-Eberhard, 1989, 2003, 2005). This hypothesis has gained empirical support in recent years through research that examined inducible plasticity in lineages within a phylogenetic context (Kerschbaumer et al., 2011; Kolbe \& Losos, 2005; Losos et al., 2000; Meyer, 1987b; Muschick, Indermaur, \& Salzburger, 2012; Tebbich et al., 2010; Wund et al., 2008, 2012). Through comparing the impacts of diet manipulation (hard vs. soft diets) 
(a) genetic assimilation
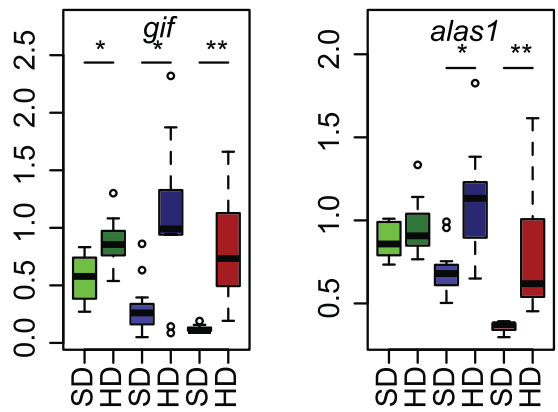

(c) Basal, plastic species

(b) genetic accommodation
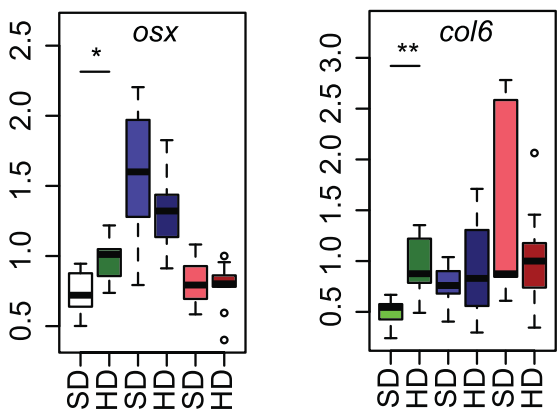

(d)

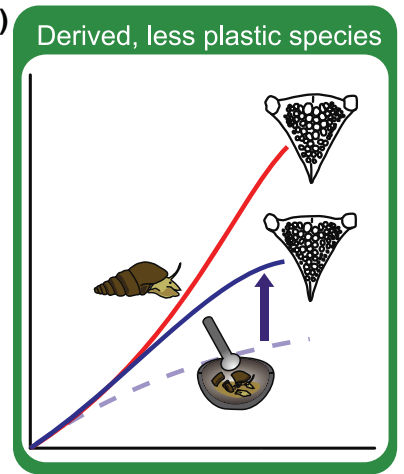

(e)

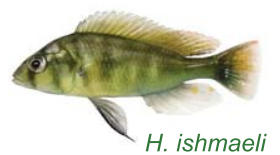

(f)
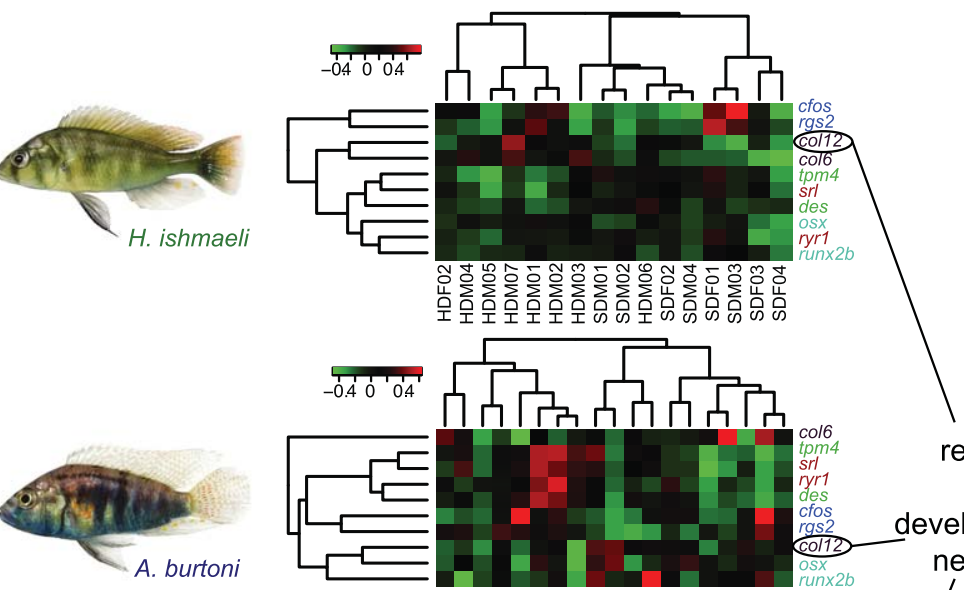

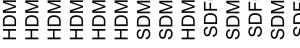
accommodation, potentially to induce altered new adaptive responses. In general, gene expression clusters by gene functional category for individuals fed a hard or soft diet for (e) $\mathrm{H}$. ishmaeli, (f) A. burtoni and (g) A. alluaudi. HDM, hard diet male; HDF, hard diet female; SDM, soft diet female; SDF, soft diet female. Coloration of gene names refers to functional class: immediate early genes are blue, calcium pathway genes are red, muscle-related genes are green, matrixrelated genes are violet, and bone-related genes are cyan. Deviations in clustering among species (e.g., col12) may indicate a rewiring of the underlying gene regulatory network in more specialized species

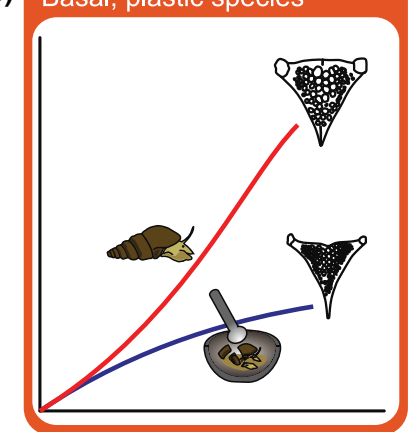

FIGURE 6 Analysis of gene expression candidate gene expression suggest speciesregulatory networks. Dampened norms of reaction in gene expression found in gif assimilation in more specialized species (c, d) while steeper slopes in osx and col6 in more specialized species (b) suggest on morphology and gene expression in a range of East African cichlid species, we demonstrate that (i) proxies of the founders of the adaptive radiation are highly plastic in an adaptive trait (LPJ molariform/papilliform morphologies) and (ii) that plasticity at that trait is lower in the studied members of the adaptive radiations and (iii) we identify transcripts that have potentially undergone genetic assimilation. (g)

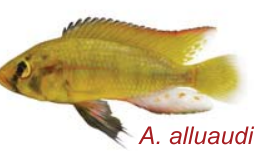

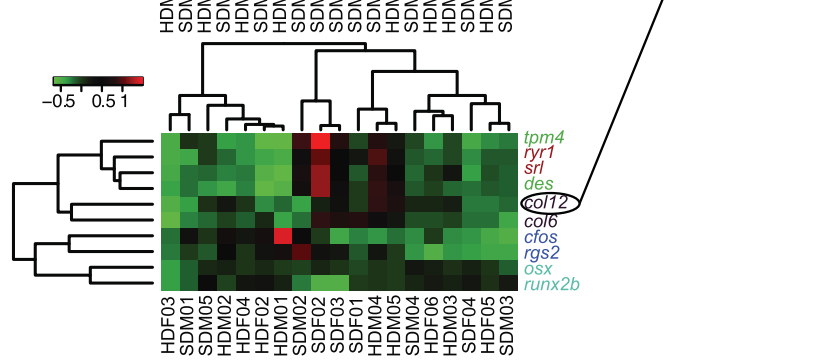

It has been proposed that adaptive radiations should, in part, be driven by competitive interactions, as indicated by ecological character displacement (Schluter, 2000; but see [Stuart \& Losos, 2013]). Indeed, the LPJs of the cichlid species included in our study predominantly occupy unique phenotype space, which is most likely caused by their distinct gene expression patterns. Such differences in LPJ shape tend to arise convergently among cichlids and are correlated rewiring

of developmental networks 
with differences in feeding efficiency on different diets (Elmer et al., 2014; Kusche, Recknagel, Elmer, \& Meyer, 2014; Muschick et al., 2012). Interestingly, the sizes and shapes of $A$. alluaudi and $H$. ishmaeli's LPJs differ only subtly and they occupy what would appear to be the same ecological niche (both are pharyngeal mollusc crushers), albeit there may be fine-grained differences between them. Ecological separation of these two species is plausible in the wild, as they occupy slightly different spatial (Abila, 2011) and bathymetric environments (Witte, 1981), and may have a preference for different prey size classes (Slootweg, 1987). It is plausible that any of the $>13$ molluscivorous species in the Mwanza Gulf may show subtle, unappreciated differences in the micro-environment and niche inhabited (Witte, 1981). Such minor differences reduce direct competition between these species and may be important in enabling such explosive adaptive radiations. It should be noted, however, that Astatoreochromis alluaudi has a wide distribution in rivers and lakes (including Lake Victoria and its swampy satellite lakes), whereas $H$. ishmaeli is endemic to Lake Victoria (Slootweg, 1987; Witte, 1981). It is unknown whether their trophic niches would overlap completely if their geographic distributions were identical.

In addition to the observed species-level differences between LPJ morphologies, the phenotype space occupied by three of our five examined species was significantly expanded through diet-induced phenotypic plasticity. This reflects an adaptive response in $A$. alluaudi and likely, to a somewhat lesser extent, in $\mathrm{H}$. ishmaeli and A. burtoni. Expanding the expressed phenotype to match available food resources is likely to confer a competitive advantage in terms of responding to seasonal and spatial variation in food availability, leading to local adaptation, albeit this was not explicitly tested in our study. Indeed, similar studies on different species have shown a putative advantage to adaptive phenotypic plasticity such as predator avoidance phenotypes in tadpoles (Pfennig \& Murphy, 2000, 2002), drought tolerance in plants (Sultan, Barton, \& Wilczek, 2009), and trophic polymorphisms in goodeid fish (Grudzien \& Turner, 1984), arctic charr (Nordeng, 1983) and stickleback (Day, Pritchard, \& Schluter, 1994; Svanbäck \& Schluter, 2012; Wund et al., 2008). Although it is clear that phenotypic plasticity may increase niche width, the issue of whether adaptive plasticity promotes or hinders evolution remains a topic of debate (Hendry, 2016), perhaps because it is a question better treated on a case-bycase basis rather than as subject to a general rule.

In the few empirical studies that have directly assessed the role of phenotypic plasticity in evolution to date, some have indicated a role for plasticity (Schaum \& Collins, 2014) and some have not (Torres-Dowdall, Handelsman, Reznick, \& Ghalambor, 2012). It is likely that both responses might, under different ecological and evolutionary scenarios, lead to different outcomes. Thus, Hendry (2016) stresses that future research should aim to tease apart the conditions under which adaptive plasticity promotes or constrains speciation. Many studies have examined the temporal and spatial grain of environmental variability under which plasticity is expected to be favoured (Ghalambor et al., 2007; Scheiner, 1998; Snell-Rood et al., 2010; Stomp et al., 2008; Van Tienderen, 1997; Via \& Lande, 1985; West-Eberhard, 1989).
Our data-set supports the hypothesis that ancestral plasticity may have been canalized during the formation of the cichlid adaptive radiations, in particular because the basal, generalist molluscivore A. alluaudi shows a higher level of inducible plasticity than the derived, specialist molluscivore, $H$. ishmaeli. Across the size and shape datasets, we observed the highest level of adaptive plasticity the LPJ of A. alluaudi (i.e., the highest level of statistical significance for the highest number of measured variables), an intermediate level in A. burtoni, a slightly lower level in $\mathrm{H}$. ishmaeli, and almost none for T. moorii (an algal scraping specialist) or $P$. multicolor. Adaptive plasticity is well documented in A. alluaudi (Greenwood, 1965; Hoogerhoud, 1986a,b; Huysseune, 1995; Huysseune et al., 1994; Smits, 1996; Smits et al., 1996); however, diet-induced LPJ plasticity was not previously demonstrated in $\mathrm{H}$. ishmaeli or $\mathrm{A}$. burtoni to the best of our knowledge. The detection of lower plasticity in the LPJ of $H$. ishmaeli than A. alluaudi suggests that genetic assimilation has commenced in this lineage, but is incomplete. Moreover, our findings imply that LPJ plasticity may be more pronounced among the riverine, more generalist and more basal cichlid lineages - an intriguing hypothesis whose testing would require further, future studies. The observation of slightly higher plasticity in the LPJ of $A$. burtoni than of $H$. ishmaeli is of particular interest, as $\mathrm{H}$. ishmaeli has a considerably more molariform jaw than A. burtoni (Hoogerhoud, 1986a), which is better suited to cracking snails, enabling a more effective exploitation of the experimental (hard) diet from the outset (Slootweg, 1987). The lack of plasticity in the LPJ of the basal generalist $P$. multicolor is most likely because this is a dwarf species with jaw muscles that are likely to be too small to crack hard snail shells. Indeed, its mean SL at the termination of the experiment was $44.6 \mathrm{~mm}$ - considerably less than the $\mathrm{SL}$ at which A. alluaudi first displayed significant LPJ plasticity $(55-60 \mathrm{~mm})$ in our previous developmental study on A. alluaudi (Schneider et al., 2014). The examination of additional basal representatives is especially important due to this unexpected result, keeping the caveat in mind that one would be investigating plasticity in extant lineages.

Our observation of generally higher plasticity in the more basal, riverine lineages, particularly in comparison with $\mathrm{H}$. ishmaeli, provides support for the hypothesis that the cichlid radiations have been initiated by flexible stem lineages (Muschick et al., 2011; Parsons et al., 2016), as was suggested for other adaptive radiations (Tebbich et al., 2010; West-Eberhard, 2003; Wund et al., 2008). The potential that a flexible stem lineage has formed the East African cichlid radiations is particularly appealing as they have evolved multitudinous phenotypes in parallel, which may have involved hypervariable flexible stems (West-Eberhard, 2003), rather than the more limited polymorphic flexibility displayed by the other well studied lineages such as sticklebacks (Rundle, Nagel, Boughman, \& Schluter, 2000). It is likely that adaptation to these multidimensional, specialized trophic niches has involved concomitant changes in learning and behaviour on top of, or instead of morphology (Meyer, 1986, 1987a), as behavioural changes have the potential to directly influence morphology through processes such as bone modelling and remodelling (Currey, 2002). Although a behavioural component was not incorporated into our study design, we observed that species such as A. alluaudi, A. burtoni 
and $H$. ishmaeli reacted to the offered novel diets more readily and enthusiastically than the other species, particularly T. moorii (pers. obs. H. Gunter). It is plausible that behavioural differences between the species (particularly in T. moorii) may have contributed to the different levels of phenotypic plasticity in their LPJs.

In addition to interpreting our results in light of the flexible stem hypothesis, we are also able to make a broader comparison of generalist and specialist lineages. Our results show that generalist (basal) lineages (A. alluaudi and A. burtoni) display a higher level of plasticity than the more derived, specialist lineages ( $H$. ishmaeli and T. moorii), in line with previous studies (Sultan et al., 2009; Svanbäck \& Schluter, 2012), and with the niche variation hypothesis (Van Valen, 1965). Our results support the hypothesis that stem lineages leading to adaptive radiations contain generalist ancestral lineages, just as was found in earlier studies (Nosil, 2002) and models (Stomp et al., 2008; Van Tienderen, 1997); however, there are many exceptions, where specialists give rise to adaptive radiations, particularly among phytophagous insects such as Hawaiian drosophila (Schluter, 2000; West-Eberhard, 2003). Based on quantitative genetic models, phenotypic plasticity is likely to be lower in specialist species (Van Tienderen, 1997), and therefore, other factors such as standing genetic variation or de novo mutations may play a relatively larger role in these instances. However, West-Eberhard (2003) shows how flexible stem plasticity in behaviour and physiology could have played a role in the adaptive diversification of Hawaiian drosophila in addition to African cichlids and other fish taxa discussed in Schluter (2000). This is especially true for radiations seeded by the colonization of novel environments such as islands, where induced plasticity could unlock cryptic genetic variation (Ledón-Rettig et al., 2014; Queitsch, Sangster, \& Lindquist, 2002; Rutherford \& Lindquist, 1998) that would not otherwise have been exposed to natural selection (Schneider \& Meyer, 2017).

While A. alluaudi and A. burtoni can be broadly described as generalist species, they show between population dietary differences, which would favour the maintenance of plasticity, given sufficient gene flow. A. burtoni shows lake-stream divergence that is determined through both genetic and plastic mechanisms, with lake fish consuming a plant/algae and zooplankton-biased diet, and stream fish consuming more snails, insects and plant seeds (Theis et al., 2014). Also, A. alluaudi's Lake Victoria populations are strictly molluscivorous (Bouton, Seehausen, \& Alphen, 1997), while riverine and satellite lake species also feed on insects, algae and fish, whose proportions vary spatially (Abila et al., 2008; Binning \& Chapman, 2008; Mbabazi, Ogutu-Ohwayo, Wandera, \& Kiziito, 2004) and seasonally (Binning, Chapman, \& Cosandey-Godin, 2009). It is possible that the broader distribution of these lineages has resulted in independent selection for higher plasticity, and basal plasticity is a more parsimonious explanation due to their phylogenetic positions. Although the Lake Victoria A. alluaudi populations are exclusively molluscivorous, this is not their preferred diet (Slootweg, 1987; Slootweg et al., 1994). Their occupation of this niche is most likely the result of intense competition (Bouton et al., 1997), whereby Lake Victoria's endemic, specialized cichlid species have a competitive advantage over A. alluaudi. So although LPJ plasticity is likely to benefit $A$. alluaudi by expanding its geographic distribution, it potentially comes at the expense of access to their preferred food items in regions of high competition. It should be noted that a single $A$. alluaudi population (from Lake Victoria) was used in this study, and we do not know how its plasticity compares to that of riverine and satellite lake populations. However, it seems likely that the other populations are plastic to an equal or greater degree than our experimental population, as riverine populations have been shown to ingest a more variable diet (Binning \& Chapman, 2008; Binning, Chapman, \& Dumont, 2010; Binning et al., 2009; Cosandey-Godin et al., 2008), so contemporary plasticity may be more beneficial.

Our study identified putative candidates for genetic assimilation. Two of these show higher inducibility in response to the plastic stimulus in the basal species A. alluaudi but not in the specialist, $\mathrm{H}$. ishmaeli potentially explaining the lower plasticity of this species. These genes are gif and alas1 and are involved in vitamin B12 absorption in the gut (Booth \& Mollin, 1959; Greibe, Fedosov, \& Nexo, 2012) and heme biosynthesis (Sadlon, Dell'Oso, Surinya, \& May, 1999), respectively. Their roles in cichlid LPJ plasticity are not yet known. Interestingly, these genes were also identified as being significant in the multiple regression analysis, which shows that they are also likely to relate to species-level differences in the plastic response. Additionally, we identified two genes that showed a pattern opposite to genetic assimilation (osx and col6), which are involved in the differentiation of osteoblasts (Nakashima \& de Crombrugghe, 2003; Nakashima et al., 2002) and form part of the bone matrix, respectively (Christensen et al., 2012). This suggests that our candidate genes display multidirectional patterns of regulatory evolution. Moreover, we identified potential genetic assimilation in patterns of gene co-expression. Specifically, col6 was co-expressed with col12 in A. alluaudi and $H$. ishmaeli, but no other genes in $A$. burtoni. These differences may have modified the stiffness of the extracellular matrix, leading to altered patterns of bone cell differentiation (Engler, Sen, Sweeney, \& Discher, 2006; McBeath, Pirone, Nelson, Bhadriraju, \& Chen, 2004) and/or altered mineralization (Wang et al., 2012), which may impact the mechanical properties of the bone (Nair, Gautieri, Chang, \& Buehler, 2013). Interestingly, col6, col12 and the IER genes are predicted to contain binding sites for the mechanically responsive transcription factor AP1 in their promoter regions (Schneider et al., 2014). Thus, our observed changes in inducible plasticity may be underlain by promoter evolution, a notion that is supported by theoretical (Espinosa-Soto, Martin, \& Wagner, 2011; Schlichting \& Pigliucci, 1993) and empirical evidence ([Li et al., 2006; Suzuki \& Nijhout, 2006; Ghalambor et al., 2015]; but see [Sikkink, Reynolds, Ituarte, Cresko, \& Phillips, 2014]). Our study analysed a small portion of the transcriptome so we cannot infer the proportion of the genome that may have undergone genetic assimilation, or whether phenotypic plasticity is promoted through largely overlapping or unique mechanisms among these species.

Our putative identification of genetically assimilated loci within a cichlid adaptive radiation represents an important step in establishing a mechanism by which plasticity may have promoted their explosive speciation (Stauffer \& van Snick Gray, 2004). This adds to other recent 
studies that have demonstrated that selection on plastic loci may have contributed to adaptive diversification in other species (Ghalambor et al., 2015). Our work will enable future investigations that pinpoint the loci associated with reduced plasticity in $\mathrm{H}$. ishmaeli and will open the door to comparative studies investigating other genetically assimilated loci in other Lake Victoria cichlid species. As these species display vast differences in LPJ shape, it is plausible that different loci would have been fixed through genetic assimilation. Comparisons between various species with different LPJ sizes and shapes will allow us to differentiate the loci associated with LPJ architecture, versus those that modulate phenotypic plasticity itself. It would also be very interesting to compare trophically equivalent species from different African lakes that are of different ages, as a means of studying various stages of genetic assimilation. For example, the Lake Victoria radiation is $\sim 100,000$ years old and the Tanganyika cichlid radiations are 9$12 \mathrm{M}$ years old (Elmer et al., 2009; Friedman et al., 2013; Genner et al., 2007; Koblmüller, Sefc, \& Sturmbauer, 2009; Verheyen, Salzburger, Snoeks, \& Meyer, 2003). The highly specialized morphology of $T$. moorii hints that longer evolutionary time periods are associated with more specialized, canalized morphologies. However, solid evidence of this requires the comparison of trophically equivalent (snail crushing) species from Lake Tanganyika. This research will add to previous studies that have identified important loci that might be responsible for traits that are conducive for the formation of adaptive radiations in general (Abzhanov, Protas, Grant, Grant, \& Tabin, 2004; Albertson \& Kocher, 2006; Chan et al., 2010; Colosimo et al., 2005), with the added benefit of providing correlative evidence that phenotypic plasticity may have played a role in the initial accumulation and selection of these mutations.

One potential objection to the hypothesis that the formation of the cichlid adaptive radiations was facilitated by phenotypic plasticity is that it would be self-limiting, as genetic assimilation would restrict phenotypic plasticity, thus preventing further plasticity-mediated evolution. On the contrary, West-Eberhard (2003) argues that hypervariable flexible stems, such as those of cichlids have "the potential to rapidly evolve in any variety of new directions, should conditions change." Indeed, rapid evolution of increased plasticity has been observed in lineages under strong selection pressure (Nussey, Postma, Gienapp, \& Visser, 2005). This scenario is backed up by the results of a range of experiments involving pond-based and natural populations, which indicate that adaptive traits fluctuate over extremely short timescales (year to year), with phenotypic plasticity providing the most plausible explanation (Kishe-Machumu, Witte, \& Wanink, 2008; van Rijssel \& Witte, 2013; van Rijssel et al., 2015). This initial flexibility might have assisted the evolution of cichlid diversification as they are clearly dominating the East African lakes in terms of biodiversity.

\section{5 | CONCLUSION}

Our investigation has provided support for the hypothesis that initial phenotypic plasticity has the potential to expand niche space and resist extinction, while later, during the formation of adaptive radiations, this plasticity can be lost and possibly become canalized into more stereotypical phenotypes of many derived species through the process of genetic assimilation. We find that derived, specialist lineages from cichlid adaptive radiations show reduced phenotypic plasticity compared to generalist lineages from outside of, and basal to, the adaptive radiations. Although it is not likely that all adaptive radiations are seeded by plastic generalist lineages, our result suggests that this scenario may be more common in adaptive radiations that were seeded by hyperflexible stem lineages that originally occupied fluctuating environments. Furthermore, through comparative gene expression studies, we have identified several putative candidates that may have undergone genetic assimilation, providing a potential genetic explanation for the reduced phenotypic plasticity displayed by the derived lineages. This research suggests that future studies should examine the selection of genetically assimilated loci in natural populations, a powerful next step in establishing a role for phenotypic plasticity in the formation of adaptive radiations - still a much debated hypothesis with only limited genetic evidence to date.

\section{ACKNOWLEDGEMENTS}

We wish to acknowledge the funding agencies that generously provided funding for this work, including the Deutsche Forschungsgemeinschaft (to HG and AM [SPP 1819]), the Zukunftskolleg at the University of Konstanz (HG), The University of Konstanz (HG and AM), Frospects (IK), Austrian Science Fund grant P22737 (CS) and the International Max Planck Research School (RS). Hans Hoffman, (the late) Frans Witte, Erwin Schraml, Thomas Uecker and Marco Welss generously supplied fish used in this study and to Sabine Urban for providing the photo of $P$. multicolor for our figures. Three reviewers provided valuable feedback on an earlier version of this manuscript, and we thank them for their insights and effort.

\section{DATA ACCESSIBILITY}

Data available from the Dryad Digital Repository: https://doi.org/10. 5061/dryad.84b09. Data files include raw relative gene expression data for qRT-PCR and linear and geometric morphometrics analyses.

\section{AUTHOR CONTRIBUTION}

H.M.G., A.M. and C.S. designed the study, and experimental work was carried out by I.K. and H.M.G. Data analysis was performed by R.F.S., I.K. and H.M.G. The initial draft of this manuscript was prepared by H.M.G. and R.F.S. and all authors assisted with additional drafts and reviewed the final version.

\section{ORCID}

Helen M. Gunter (iD http://orcid.org/0000-0002-6557-1993 Ralf F. Schneider (DD http://orcid.org/0000-0001-6015-7219 Christian Sturmbauer (ID https://orcid.org/0000-0003-4170-2765 Axel Meyer (D) http://orcid.org/0000-0002-0888-8193 


\section{REFERENCES}

Abila, R. (2011). Preliminary gut content and dentition analysis reveal subtle resource partitioning and feeding adaptations within a haplochromine cichlid community of Lake Victoria Satellite Lake. African Journal of Environmental Science and Technology, 5, 457-463.

Abila, R., Salzburger, W., Ndonga, M. F., Owiti, D. O., Barluenga, M., \& Meyer, A. (2008). The role of the Yala swamp lakes in the conservation of Lake Victoria region haplochromine cichlids: Evidence from genetic and trophic ecology studies. Lakes \& Reservoirs: Research \& Management, 13, 95-104. https://doi.org/10.1111/j.1440-1770.2008.00366.x

Abzhanov, A., Protas, M., Grant, B. R., Grant, P. R., \& Tabin, C. J. (2004). Bmp4 and morphological variation of beaks in Darwin's finches. Science, 305, 1462-1465. https://doi.org/10.1126/science.1098095

Adams, D. C., \& Otárola-Castillo, E. (2013). geomorph: An R package for the collection and analysis of geometric morphometric shape data. Methods in Ecology and Evolution, 4, 393-399. https://doi.org/10. 1111/mee3.2013.4.issue-4

Albertson, R. C., \& Kocher, T. D. (2006). Genetic and developmental basis of cichlid trophic diversity. Heredity, 97, 211-221. https://doi.org/10. 1038/sj.hdy.6800864

Albertson, R., Markert, J., Danley, P., \& Kocher, T. (1999). Phylogeny of a rapidly evolving clade: The cichlid fishes of Lake Malawi, East Africa. Proceedings of the National Academy of Sciences, 96, 5107-5110. https://doi.org/10.1073/pnas.96.9.5107

Baldwin, J. M. (1896). A new factor in evolution. The American Naturalist, 30, 441-451. https://doi.org/10.1086/276408

Binning, S. A., \& Chapman, L. J. (2008). Feeding ecology and diet overlap in riverine cichlids from western Uganda. Internationale Vereinigung fur Theoretische und Angewandte Limnologie Verhandlungen, 30, 283286.

Binning, S., Chapman, L., \& Cosandey-Godin, A. (2009). Specialized morphology for a generalist diet: Evidence for Liem's paradox in a cichlid fish. Journal of Fish Biology, 75, 1683-1699. https://doi.org/10.1111/ jfb.2009.75.issue-7

Binning, S. A., Chapman, L. J., \& Dumont, J. (2010). Feeding and breathing: Trait correlations in an African cichlid fish. Journal of Zoology, 282, 140-149.

Booth, C., \& Mollin, D. (1959). The site of absorption of vitamin B12 in man. The Lancet, 273, 18-21. https://doi.org/10.1016/S0140-6736 (59)90979-1

Bouton, N., Seehausen, O., \& Alphen, J. J. M. (1997). Resource partitioning among rock-dwelling haplochromines (Pisces: Cichlidae) from Lake Victoria. Ecology of Freshwater Fish, 6, 225-240. https://doi.org/10. 1111/eff.1997.6.issue-4

Bouton, N., Witte, F., \& Van Alphen, J. J. M. (2002). Experimental evidence for adaptive phenotypic plasticity in a rock-dwelling cichlid fish from Lake Victoria. Biological Journal of the Linnean Society, 77, 185192. https://doi.org/10.1046/j.1095-8312.2002.00093.x

Brawand, D., Wagner, C. E., Li, Y. I., Malinsky, M., Keller, I., Fan, S., ... Simakov, O. (2014). The genomic substrate for adaptive radiation in African cichlid fish. Nature, 513, 375-381. https://doi.org/10. 1038/nature13726

Carroll, S. P., Dingle, H., \& Klassen, S. P. (1997). Genetic differentiation of fitness-associated traits among rapidly evolving populations of the soapberry bug. Evolution, 51, 1182-1188. https://doi.org/10.1111/j. 1558-5646.1997.tb03966.x

Carroll, S. P., Klassen, S. P., \& Dingle, H. (1998). Rapidly evolving adaptations to host ecology and nutrition in the soapberry bug. Evolutionary Ecology, 12, 955-968. https://doi.org/10.1023/a: 1006568206413

Chan, Y. F., Marks, M. E., Jones, F. C., Villarreal Jr, G., Shapiro, M. D., Brady, S. D., ... Kingsley, D. M. (2010). Adaptive evolution of pelvic reduction in sticklebacks by recurrent deletion of a Pitx1 enhancer. Science, 327, 302-305. https://doi.org/10.1126/science.1182213
Chapman, L., Galis, F., \& Shinn, J. (2000). Phenotypic plasticity and the possible role of genetic assimilation: Hypoxia-induced trade-offs in the morphological traits of an African cichlid. Ecology Letters, 3, 387393. https://doi.org/10.1046/j.1461-0248.2000.00160.x

Christensen, S. E., Coles, J. M., Zelenski, N. A., Furman, B. D., Leddy, H. A., Zauscher, S., ... Guilak, F. (2012). Altered trabecular bone structure and delayed cartilage degeneration in the knees of collagen VI null mice. PLoS ONE, 7, e33397. https://doi.org/10.1371/journal. pone.0033397

Clabaut, C., Bunje, P. M., Salzburger, W., \& Meyer, A. (2007). Geometric morphometric analyses provide evidence for the adaptive character of the Tanganyikan cichlid fish radiations. Evolution, 61, 560-578. https://doi.org/10.1111/j.1558-5646.2007.00045.x

Colosimo, P. F., Hosemann, K. E., Balabhadra, S., Villarreal Jr, G., Dickson, M., Grimwood, J., ... Kingsley, D. M. (2005). Widespread parallel evolution in sticklebacks by repeated fixation of ectodysplasin alleles. Science, 307, 1928-1933. https://doi.org/10.1126/science.1107239

Cook, S. A., \& Johnson, M. P. (1968). Adaptation to heterogeneous environments. I. Variation in heterophylly in Ranunculus flammula L. Evolution, 22(3), 496-516. https://doi.org/10.1111/j.1558-5646.1968.tb03988.x

Cosandey-Godin, A., Binning, S. A., \& Chapman, L. J. (2008). Specialized morphology for a non-specialized diet: Liem's paradox in an African cichlid fish. McGill Science Undergraduate Research Journal, 3, 19-23.

Crispo, E. (2007). The Baldwin effect and genetic assimilation: Revisiting two mechanisms of evolutionary change mediated by phenotypic plasticity. Evolution, 61, 2469-2479. https://doi.org/10.1111/j.15585646.2007.00203.x

Crispo, E., \& Chapman, L. J. (2008). Population genetic structure across dissolved oxygen regimes in an African cichlid fish. Molecular Ecology, 17, 2134-2148. https://doi.org/10.1111/j.1365-294x.2008.03729.x

Crispo, E., \& Chapman, L. (2010). Geographic variation in phenotypic plasticity in response to dissolved oxygen in an African cichlid fish. Journal of Evolutionary Biology, 23, 2091-2103. https://doi.org/10. 1111/j.1420-9101.2010.02069.x

Currey, J. D. (2002). Bones: Structure and mechanics. Princeton, NJ: Princeton University Press.

Day, T., Pritchard, J., \& Schluter, D. (1994). A comparison of 2 sticklebacks. Evolution, 48, 1723-1734. https://doi.org/10.1111/j.15585646.1994.tb02208.x

De Jong, G. (2005). Evolution of phenotypic plasticity: Patterns of plasticity and the emergence of ecotypes. New Phytologist, 166, 101-118. https://doi.org/10.1111/j.1469-8137.2005.01322.x

DeWitt, T. J., Robinson, B. W., \& Wilson, D. S. (2000). Functional diversity among predators of a freshwater snail imposes an adaptive trade-off for shell morphology. Evolutionary Ecology Research, 2, 129-148.

Elmer, K. R., Fan, S., Kusche, H., Spreitzer, M. L., Kautt, A. F., Franchini, P., \& Meyer, A. (2014). Parallel evolution of Nicaraguan crater lake cichlid fishes via non-parallel routes. Nature Communications, 5, 5168. https://doi.org/10.1038/ncomms6168

Elmer, K. R., Reggio, C., Wirth, T., Verheyen, E., Salzburger, W., \& Meyer, A. (2009). Pleistocene desiccation in East Africa bottlenecked but did not extirpate the adaptive radiation of Lake Victoria haplochromine cichlid fishes. Proceedings of the National Academy of Sciences, 106, 13404-13409. https://doi.org/10.1073/pnas.0902299106

Engler, A. J., Sen, S., Sweeney, H. L., \& Discher, D. E. (2006). Matrix elasticity directs stem cell lineage specification. Cell, 126, 677-689. https://doi.org/10.1016/j.cell.2006.06.044

Espinosa-Soto, C., Martin, O. C., \& Wagner, A. (2011). Phenotypic plasticity can facilitate adaptive evolution in gene regulatory circuits. BMC Evolutionary Biology, 11, 5. https://doi.org/10.1186/1471-2148-11-5

Friedman, M., Keck, B. P., Dornburg, A., Eytan, R. I., Martin, C. H., Hulsey, C. D., ... Near, T. J. (2013). Molecular and fossil evidence place the origin of cichlid fishes long after Gondwanan rifting. Proceedings of the Royal Society B: Biological Sciences, 280, 20131733. https://doi. org/10.1098/rspb.2013.1733 
Genner, M. J., Seehausen, O., Lunt, D. H., Joyce, D. A., Shaw, P. W., Carvalho, G. R., \& Turner, G. F. (2007). Age of cichlids: New dates for ancient lake fish radiations. Molecular Biology and Evolution, 24, 1269-1282. https://doi.org/10.1093/molbev/msm050

Ghalambor, C. K., Hoke, K. L., Ruell, E. W., Fischer, E. K., Reznick, D. N., \& Hughes, K. A. (2015). Non-adaptive plasticity potentiates rapid adaptive evolution of gene expression in nature. Nature, 525, 373375. https://doi.org/10.1038/nature15256

Ghalambor, C. K., McKay, J. K., Carroll, S. P., \& Reznick, D. N. (2007). Adaptive versus non-adaptive phenotypic plasticity and the potential for contemporary adaptation in new environments. Functional Ecology, 21, 394 407. https://doi.org/10.1111/j.1365-2435.2007.01283.x

Gomez-Mestre, I., \& Jovani, R. (2013). A heuristic model on the role of plasticity in adaptive evolution: Plasticity increases adaptation, population viability and genetic variation. Proceedings of the Royal Society B: Biological Sciences, 280, 20131869. https://doi.org/10.1098/rspb. 2013.1869

Greenwood, P. (1959). The monotypic genera of cichlid fishes in Lake Victoria, Part II. Bulletin of the Natural History Museum Zoology Series, 7, 163-177.

Greenwood, P. H. (1965). Environmental effects on the pharyngeal mill of a cichlid fish, Astatoreochromis alluaudi, and their taxonomic implications. Journal of the Proceedings of the Linnean Society Zoology, 176, 1-10. https://doi.org/10.1111/j.1095-8312.1965.tb00932.x

Greibe, E., Fedosov, S., \& Nexo, E. (2012). The cobalamin-binding protein in zebrafish is an intermediate between the three cobalamin-binding proteins in human. PLoS ONE, 7, e35660. https://doi.org/10.1371/ journal.pone.0035660

Grudzien, T. A., \& Turner, B. J. (1984). Direct evidence that the llyodon morphs are a single biological species. Evolution, 38, 402-407. https://doi.org/10.1111/j.1558-5646.1984.tb00298.x

Gunter, H. M., Fan, S., Xiong, F., Franchini, P., Fruciano, C., \& Meyer, A. (2013). Shaping development through mechanical strain: The transcriptional basis of diet-dependent phenotypic plasticity in a cichlid fish. Molecular Ecology, 22, 4516-4531. https://doi.org/10.1111/mec. 12417

Haas, B. J., Papanicolaou, A., Yassour, M., Grabherr, M., Blood, P. D., Bowden, J., ... Regev, A. (2013). De novo transcript sequence reconstruction from RNA-seq using the Trinity platform for reference generation and analysis. Nature Protocols, 8, 1494-1512. https://doi.org/ 10.1038/nprot.2013.084

Hedrick, P. W. (2013). Adaptive introgression in animals: Examples and comparison to new mutation and standing variation as sources of adaptive variation. Molecular Ecology, 22, 4606-4618. https://doi.org/ 10.1111/mec.12415

Hendry, A. P. (2016). Key questions on the role of phenotypic plasticity in eco-evolutionary dynamics. Journal of Heredity, 107, 25-41. https://doi.org/10.1093/jhered/esv060

Henning, F., \& Meyer, A. (2014). The evolutionary genomics of cichlid fishes: Explosive speciation and adaptation in the postgenomic era. Annual Review of Genomics and Human Genetics, 15, 417-441. https://doi.org/10.1146/annurev-genom-090413-025412

Holden, K. K., \& Bruton, M. N. (1994). The early ontogeny of the southern mouthbrooder, Pseudocrenilabrus philander (Pisces, Cichlidae). Environmental Biology of Fishes, 41, 311-329. https://doi.org/10. 1007/978-94-011-0199-8_24

Hoogerhoud, R. J. C. (1986a) Ecological morphology of some cichlid fishes. PhD thesis, Leiden University.

Hoogerhoud, R. J. C. (1986b). Taxonomic and ecological aspects of morphological plasticity in molluscivorous haplochromines (Pisces, Cichlidae). Annales de la Musée royale Afrique centrale Tervuren, Sciences Zoologique, 251, 131-134.

Hulsey, C. D., Hendrickson, D. A., \& de León, F. G. (2005). Trophic morphology, feeding performance and prey use in the polymorphic fish Herichthys minckleyi. Evolutionary Ecology Research, 7, 303-324.
Huysseune, A. (1995). Phenotypic plasticity in the lower pharyngeal jaw dentition of Astatoreochromis alluaudi (Teleostei, Cichlidae). Archives of Oral Biology, 40, 1005-1014. https://doi.org/10.1016/0003-9969 (95)00074-y

Huysseune, A., Sire, J. Y., \& Meunier, F. J. (1994). Comparative-study of lower pharyngeal jaw structure in 2 phenotypes of Astatoreochromis alluaudi (Teleostei, Cichlidae). Journal of Morphology, 221, 25-43. https://doi.org/10.1002/jmor.1052210103

Jarosz, D. F., \& Lindquist, S. (2010). Hsp90 and environmental stress transform the adaptive value of natural genetic variation. Science, 330, 1820-1824. https://doi.org/10.1126/science.1195487

Kerschbaumer, M., Postl, L., Koch, M., Wiedl, T., \& Sturmbauer, C. (2011). Morphological distinctness despite large-scale phenotypic plasticity - analysis of wild and pond-bred juveniles of allopatric populations of Tropheus moorii. Naturwissenschaften, 98, 125-134. https://doi.org/10.1007/s00114-010-0751-2

Kishe-Machumu, M., Witte, F., \& Wanink, J. H. (2008). Dietary shift in benthivorous cichlids after the ecological changes in Lake Victoria. Animal Biology, 58, 401-417. https://doi.org/10.1163/ $157075608 \times 383700$

Koblmüller, S., Sefc, K. M., \& Sturmbauer, C. (2009). The Lake Tanganyika cichlid species assemblage: Recent advances in molecular phylogenetics. In T. Wilke, R. Väinolä, \& F. Riedel (Eds.), Patterns and processes of speciation in Ancient lakes (pp. 5-20). The Netherlands: Springer.

Kolbe, J. J., \& Losos, J. B. (2005). Hind-limb length plasticity in Anolis carolinensis. Journal of Herpetology, 39, 674-678. https://doi.org/10. 1670/87-05N.1

Kusche, H., Recknagel, H., Elmer, K. R., \& Meyer, A. (2014). Crater lake cichlids individually specialize along the benthic-limnetic axis. Ecology and Evolution, 4, 1127-1139. https://doi.org/10.1002/ece3.2014.4.is sue-7

Laland, K. N., Odling-Smee, J., Hoppitt, W., \& Uller, T. (2013). More on how and why: Cause and effect in biology revisited. Biology \& Philosophy, 28, 719-745. https://doi.org/10.1007/s10539-012-9335-1

Laland, K. N., Sterelny, K., Odling-Smee, J., Hoppitt, W., \& Uller, T. (2011). Cause and effect in biology revisited: Is Mayr's proximate-ultimate dichotomy still useful? Science, 334, 1512-1516. https://doi. org/10.1126/science.1210879

Lande, R. (2009). Adaptation to an extraordinary environment by evolution of phenotypic plasticity and genetic assimilation. Journal of Evolutionary Biology, 22, 1435-1446. https://doi.org/10.1111/jeb.2009.22. issue-7

Ledón-Rettig, C. C., Pfennig, D. W., Chunco, A. J., \& Dworkin, I. (2014). Cryptic genetic variation in natural populations: A predictive framework. Integrative and Comparative Biology, 54, 783-793. https://doi. org/10.1093/icb/icu077

Li, Y., Álvarez, O. A., Gutteling, E. W., Tijsterman, M., Fu, J., Riksen, J. A., ... Kammenga, J. E. (2006). Mapping determinants of gene expression plasticity by genetical genomics in C. elegans. Plos Genetics, 2, e222. https://doi.org/10.1371/journal.pgen.0020222

Losos, J. B. (2010). Adaptive radiation, ecological opportunity, and evolutionary determinism. American Naturalist, 175, 623-639. https://doi. org/10.1086/652433

Losos, J. B., Creer, D. A., Glossip, D., Goellner, R., Hampton, A., Roberts, G., . Ettling, J. (2000). Evolutionary implications of phenotypic plasticity in the hindlimb of the lizard Anolis sagrei. Evolution, 54, 301-305. https://doi.org/10.1554/0014-3820(2000) 054[0301:eioppi]2.0.co;2

Lucek, K., Sivasundar, A., \& Seehausen, O. (2014). Disentangling the role of phenotypic plasticity and genetic divergence in contemporary ecotype formation during a biological invasion. Evolution, 68, 2619-2632. https://doi.org/10.1111/evo.2014.68.issue-9

Machado-Schiaffino, G., Henning, F., \& Meyer, A. (2014). Species-specific differences in adaptive phenotypic plasticity in an ecologically relevant trophic trait: Hypertrophic lips in midas cichlid fishes. Evolution, 68, 2086-2091. https://doi.org/10.1111/evo.2014.68.issue-7 
Masel, J., King, O. D., \& Maughan, H. (2006). The loss of adaptive plasticity during long periods of environmental stasis. The American Naturalist, $169,38-46$.

Mayr, E. (1961). Cause and effect in biology. Science, 134, 1501-1506. https://doi.org/10.1126/science.134.3489.1501

Mbabazi, D., Ogutu-Ohwayo, R., Wandera, S., \& Kiziito, Y. (2004). Fish species and trophic diversity of haplochromine cichlids in the Kyoga satellite lakes (Uganda). African Journal of Ecology, 42, 59-68. https://doi.org/10.1111/aje.2004.42.issue-1

McBeath, R., Pirone, D. M., Nelson, C. M., Bhadriraju, K., \& Chen, C. S. (2004). Cell shape, cytoskeletal tension, and RhoA regulate stem cell lineage commitment. Developmental Cell, 6, 483-495. https://doi.org/ 10.1016/s1534-5807(04)00075-9

Meyer, A. (1986). Changes in behavior with increasing experience with a novel prey in fry of the Central American cichlid, Cichlasoma managuense (Teleostei: Cichlidae). Behaviour, 98, 145-167. https://doi.org/ 10.1163/156853986X00946

Meyer, A. (1987a). First feeding success with two types of prey by the Central American cichlid fish, Cichlasoma managuense (Pisces, Cichlidae): Morphology versus behavior. Environmental Biology of Fishes, 18, 127-134. https://doi.org/10.1007/BF00002600

Meyer, A. (1987b). Phenotypic plasticity and heterochrony in Cichlasoma managuense (Pisces, Cichlidae) and their implications for speciation in cichlid fishes. Evolution, 41, 1357-1369.

Meyer, A. (1990a). Ecological and evolutionary consequences of the trophic polymorphism in Cichlasoma citrinellum (Pisces: Cichlidae). Biological Journal of the Linnean Society, 39, 279-299. https://doi.org/10. 1111/bij.1990.39.issue-3

Meyer, A. (1990b). Morphometrics and allometry in the trophically polymorphic cichlid fish, Cichlasoma citrinellum: Alternative adaptations and ontogenetic changes in shape. Journal of Zoology, 221, 237-260. https://doi.org/10.1111/jzo.1990.221.issue-2

Meyer, A. (1993). Trophic polymorphisms in cichlid fish: Do they represent intermediate steps during sympatric speciation and explain their rapid adaptive radiation? In J.-H. Schroder, J. Bauer, \& M. Schartl (Eds.), New trends in ichthyology (pp. 257-266). Berlin: Blackwell Scientific Publications.

Meyer, A., Kocher, T. D., Basasibwaki, P., \& Wilson, A. C. (1990). Monophyletic origin of Lake Victoria cichlid fishes suggested by mitochondrial-DNA sequences. Nature, 347, 550-553. https://doi.org/10. 1038/347550a0

Morris, M. R., Richard, R., Leder, E. H., Barrett, R. D., Aubin-Horth, N., \& Rogers, S. M. (2014). Gene expression plasticity evolves in response to colonization of freshwater lakes in threespine stickleback. Molecular Ecology, 23, 3226-3240. https://doi.org/10.1111/ mec.12820

Muschick, M., Barluenga, M., Salzburger, W., \& Meyer, A. (2011). Adaptive phenotypic plasticity in the Midas cichlid fish pharyngeal jaw and its relevance in adaptive radiation. BMC Evolutionary Biology, 11, 116. https://doi.org/10.1186/1471-2148-11-116

Muschick, M., Indermaur, A., \& Salzburger, W. (2012). Convergent evolution within an adaptive radiation of cichlid fishes. Current Biology, 22, 2362-2368. https://doi.org/10.1016/j.cub.2012.10.048

Nair, A. K., Gautieri, A., Chang, S.-W., \& Buehler, M. J. (2013). Molecular mechanics of mineralized collagen fibrils in bone. Nature Communications, 4, 1724. https://doi.org/10.1038/ncomms 2720

Nakashima, K., \& de Crombrugghe, B. (2003). Transcriptional mechanisms in osteoblast differentiation and bone formation. Trends in Genetics, 19, 458-466. https://doi.org/10.1016/S0168-9525(03)00176-8

Nakashima, K., Zhou, X., Kunkel, G., Zhang, Z., Deng, J. M., Behringer, R. R., \& de Crombrugghe, B. (2002). The novel zinc finger-containing transcription factor Osterix is required for osteoblast differentiation and bone formation. Cell, 108, 17-29. https://doi.org/10.1016/ s0092-8674(01)00622-5
Nordeng, H. (1983). Solution to the" char problem" based on Arctic char (Salvelinus alpinus) in Norway. Canadian Journal of Fisheries and Aquatic Sciences, 40, 1372-1387. https://doi.org/10.1139/f83-159

Nosil, P. (2002). Transition rates between specialization and generalization in phytophagous insects. Evolution, 56, 1701-1706. https://doi. org/10.1111/evo.2002.56.issue-8

Nussey, D. H., Postma, E., Gienapp, P., \& Visser, M. E. (2005). Selection on heritable phenotypic plasticity in a wild bird population. Science, 310, 304-306. https://doi.org/10.1126/science.1117004

Oke, K., Bukhari, M., Kaeuffer, R., Rolshausen, G., Räsänen, K., Bolnick, D. I., .. Hendry, A. P. (2016). Does plasticity enhance or dampen phenotypic parallelism? A test with three lake-stream stickleback pairs. Journal of Evolutionary Biology, 29, 126-143. https://doi.org/10.1111/jeb.12767

Parsons, K. J., Concannon, M., Navon, D., Wang, J., Ea, I., Groveas, K., ... Albertson, R. C. (2016). Foraging environment determines the genetic architecture and evolutionary potential of trophic morphology in cichlid fishes. Molecular Ecology, 25, 6012-6023. https://doi.org/10. 1111/mec.13801

Parsons, K. J., \& Robinson, B. W. (2006). Replicated evolution of integrated plastic responses during early adaptive divergence. Evolution, 60, 801-813. https://doi.org/10.1111/evo.2006.60.issue-4

Pfennig, D. W., \& Murphy, P. J. (2000). Character displacement in polyphenic tadpoles. Evolution, 54, 1738-1749. https://doi.org/10.1111/ evo.2000.54.issue-5

Pfennig, D. W., \& Murphy, P. J. (2002). How fluctuating competition and phenotypic plasticity mediate species divergence. Evolution, 56, 1217-1228. https://doi.org/10.1111/evo.2002.56.issue-6

Pfennig, D. W., Wund, M. A., Snell-Rood, E. C., Cruickshank, T., Schlichting, C. D., \& Moczek, A. P. (2010). Phenotypic plasticity's impacts on diversification and speciation. Trends in Ecology \& Evolution, 25, 459467. https://doi.org/10.1016/j.tree.2010.05.006

Pigliucci, M. (2007). Do we need an extended evolutionary synthesis? Evolution, 61, 2743-2749. https://doi.org/10.1111/evo.2007.61.is sue-12

Queitsch, C., Sangster, T. A., \& Lindquist, S. (2002). Hsp90 as a capacitor of phenotypic variation. Nature, 417, 618-624. https://doi.org/10. 1038/nature749

RC-Team (2012). R: A language and environment for statistical computing. Vienna, Austria: R Foundation for Statistical Computing.

Reznick, D. N., \& Ghalambor, C. K. (2005). Selection in nature: Experimental manipulations of natural populations. Integrative and Comparative Biology, 45, 456-462. https://doi.org/10.1093/icb/45.3. 456

Richards, C. L., Bossdorf, O., Muth, N. Z., Gurevitch, J., \& Pigliucci, M. (2006). Jack of all trades, master of some? On the role of phenotypic plasticity in plant invasions. Ecology Letters, 9, 981-993. https://doi. org/10.1111/ele.2006.9.issue-8

van Rijssel, J. C., Hoogwater, E. S., Kishe-Machumu, M. A., van Reenen, E., Spits, K. V., van der Stelt, R. C., ... Witte, F. (2015). Fast adaptive responses in the oral jaw of Lake Victoria cichlids. Evolution, 69, 179189. https://doi.org/10.1111/evo.12561

van Rijssel, J. C., \& Witte, F. (2013). Adaptive responses in resurgent Lake Victoria cichlids over the past 30 years. Evolutionary Ecology, 27, 253-267. https://doi.org/10.1007/s10682-012-9596-9

Robinson, B. W., \& Wilson, D. S. (1996). Genetic variation and phenotypic plasticity in a trophically polymorphic population of pumpkinseed sunfish (Lepomis gibbosus). Evolutionary Ecology, 10, 631-652. https://doi.org/10.1007/BF01237711

Rundle, H. D., Nagel, L., Boughman, J. W., \& Schluter, D. (2000). Natural selection and parallel speciation in sympatric sticklebacks. Science, 287, 306-308. https://doi.org/10.1126/science.287.5451.306

Rutherford, S. L., \& Lindquist, S. (1998). Hsp90 as a capacitor for morphological evolution. Nature, 396, 336-342. https://doi.org/10.1038/ 24550 
Sadlon, T. J., Dell'Oso, T., Surinya, K. H., \& May, B. K. (1999). Regulation of erythroid 5-aminolevulinate synthase expression during erythropoiesis. International Journal of Biochemistry \& Cell Biology, 31, 11531167. https://doi.org/10.1016/S1357-2725(99)00073-4

Salzburger, W. (2009). The interaction of sexually and naturally selected traits in the adaptive radiations of cichlid fishes. Molecular Ecology, 18, 169-185. https://doi.org/10.1111/mec.2009.18.issue-2

Salzburger, W., Mack, T., Verheyen, E., \& Meyer, A. (2005). Out of Tanganyika: Genesis, explosive speciation, key-innovations and phylogeography of the haplochromine cichlid fishes. BMC Evolutionary Biology, 5, 17. https://doi.org/10.1186/1471-2148-5-17

Schaum, C. E., \& Collins, S. (2014). Plasticity predicts evolution in a marine alga. Proceedings of the Royal Society of London B: Biological Sciences, 281, 20141486. https://doi.org/10.1098/rspb.2014.1486

Scheiner, S. M. (1998). The genetics of phenotypic plasticity. VII. Evolution in a spatially-structured environment. Journal of Evolutionary Biology, 11, 303-320. https://doi.org/10.1046/j.1420-9101.1998. 11030303.x

Schlichting, C. D., \& Pigliucci, M. (1993). Control of phenotypic plasticity via regulatory genes. American Naturalist, 142, 366-370. https://doi. org/10.1086/285543

Schluter, D. (1994). Experimental evidence that competition promotes divergence in adaptive radiation. Science, 266, 798. https://doi.org/ 10.1126/science.266.5186.798

Schluter, D. (2000). The ecology of adaptive radiation. Oxford: Oxford University Press.

Schneider, R. F., \& Meyer, A. (2017). How plasticity, genetic assimilation and cryptic genetic variation may contribute to adaptive radiations. Molecular Ecology, 26, 330-350. https://doi.org/10.1111/mec.13880

Schneider, R. F., Xiong, F., Li, Y., Meyer, A., \& Gunter, H. M. (2014). Regulatory networks that shape the development of adaptive phenotypic plasticity in a cichlid fish. Molecular Ecology, 23, 4511-4526. https://doi.org/10.1111/mec.12851

Seehausen, O. (2006). African cichlid fish: A model system in adaptive radiation research. Proceedings of the Royal Society of London B: Biological Sciences, 273, 1987-1998. https://doi.org/10.1098/rspb.2006. 3539

Seehausen, O., Terai, Y., Magalhaes, I. S., Carleton, K. L., Mrosso, H. D., Miyagi, R., ... Okada, N. (2008). Speciation through sensory drive in cichlid fish. Nature, 455, 620. https://doi.org/10.1038/nature07285

Sepkoski Jr, J. J. (1996). Competition in macroevolution: The double wedge revisited. In Evolutionary paleobiology (pp. 211-255). Chicago: University of Chicago Press.

Sikkink, K. L., Reynolds, R. M., Ituarte, C. M., Cresko, W. A., \& Phillips, P. C. (2014). Rapid evolution of phenotypic plasticity and shifting thresholds of genetic assimilation in the nematode Caenorhabditis remanei. G3: Genes| Genomes. Genetics, 4, 1103-1112.

Simpson G (1953) The major features of evolution. Columbia University Press, New York.

Slootweg, R. (1987). Prey selection by molluscivorous cichlids foraging on a schistosomiasis vector snail, Biomphalaria glabrata. Oecologia, 74, 193-202. https://doi.org/10.1007/BF00379359

Slootweg, R., Malek, E. A., \& Mccullough, F. S. (1994). The biological-control of snail intermediate hosts of schistosomiasis by fish. Reviews in Fish Biology and Fisheries, 4, 67-90. https://doi.org/10.1007/ BF00043261

Smits, J. D. (1996) Trophic flexibility through spatial reallocation of anatomical structures in the cichlid fish Astatoreochromis alluaudi. PhD thesis, University of Leiden.

Smits, J. D., Witte, F., \& VanVeen, F. G. (1996). Functional changes in the anatomy of the pharyngeal jaw apparatus of Astatoreochromis alluaudi (Pisces, Cichlidae), and their effects on adjacent structures. Biological Journal of the Linnean Society, 59, 389-409.

Snell-Rood, E. C., Van Dyken, J. D., Cruickshank, T., Wade, M. J., \& Moczek, A. P. (2010). Toward a population genetic framework of developmental evolution: The costs, limits, and consequences of phenotypic plasticity. BioEssays, 32, 71-81. https://doi.org/10.1002/bies. v32:1

Sollars, V., Lu, X., Xiao, L., Wang, X., Garfinkel, M. D., \& Ruden, D. M. (2003). Evidence for an epigenetic mechanism by which Hsp90 acts as a capacitor for morphological evolution. Nature Genetics, 33, 7074. https://doi.org/10.1038/ng1067

Stager, J., \& Johnson, T. (2008). The late Pleistocene desiccation of Lake Victoria and the origin of its endemic biota. Hydrobiologia, 596, 5-16. https://doi.org/10.1007/s10750-007-9158-2

Standen, E. M., Du, T. Y., \& Larsson, H. C. (2014). Developmental plasticity and the origin of tetrapods. Nature, 513, 54-58. https://doi.org/ 10.1038/nature13708

Stauffer, J. R., \& van Snick Gray, E. (2004). Phenotypic plasticity: Its role in trophic radiation and explosive speciation in cichlids (Teleostei: Cichlidae). Animal Biology, 54, 137-158. https://doi.org/10.1163/ 1570756041445191

Stomp, M., van Dijk, M. A., van Overzee, H. M., Wortel, M. T., Sigon, C. A., Egas, M., ... Huisman, J. (2008). The timescale of phenotypic plasticity and its impact on competition in fluctuating environments. The American Naturalist, 172, E169-E185. https://doi.org/10.1086/591680

Stuart, Y. E., \& Losos, J. B. (2013). Ecological character displacement: Glass half full or half empty? Trends in Ecology \& Evolution, 28, 402408. https://doi.org/10.1016/j.tree.2013.02.014

Sturmbauer, C., Hainz, U., Baric, S., Verheyen, E., \& Salzburger, W. (2003). Evolution of the tribe Tropheini from Lake Tanganyika: Synchronized explosive speciation producing multiple evolutionary parallelism. Hydrobiologia, 500, 51-64. https://doi.org/10.1023/A:1024680201436

Sturmbauer, C., Mark, W., \& Dallinger, R. (1992). Ecophysiology of Aufwuchs-eating cichlids in Lake Tanganyika: Niche separation by trophic specialization. Environmental Biology of Fishes, 35, 283-290. https://doi.org/10.1007/BF00001895

Sturmbauer, C., \& Meyer, A. (1992). Genetic divergence, speciation and morphological stasis in a lineage of African cichlid fishes. Nature, 358, 578-581. https://doi.org/10.1038/358578a0

Sultan, S. E., Barton, K., \& Wilczek, A. M. (2009). Contrasting patterns of transgenerational plasticity in ecologically distinct congeners. Ecology, 90, 1831-1839. https://doi.org/10.1890/08-1064.1

Suzuki, Y., \& Nijhout, H. F. (2006). Evolution of a polyphenism by genetic accommodation. Science, 311, 650-652. https://doi.org/10.1126/scie nce.1118888

Svanbäck, R., \& Schluter, D. (2012). Niche specialization influences adaptive phenotypic plasticity in the threespine stickleback. The American Naturalist, 180, 50-59. https://doi.org/10.1086/666000

Tebbich, S., Sterelny, K., \& Teschke, I. (2010). The tale of the finch: Adaptive radiation and behavioural flexibility. Philosophical Transactions of the Royal Society of London B: Biological Sciences, 365, 1099-1109. https://doi.org/10.1098/rstb.2009.0291

Theis, A., Ronco, F., Indermaur, A., Salzburger, W., \& Egger, B. (2014). Adaptive divergence between lake and stream populations of an East African cichlid fish. Molecular Ecology, 23, 5304-5322. https://doi. org/10.1111/mec.12939

Torres-Dowdall, J., Handelsman, C. A., Reznick, D. N., \& Ghalambor, C. K. (2012). Local adaptation and the evolution of phenotypic plasticity in Trinidadian guppies (Poecilia reticulata). Evolution, 66, 3432-3443. https://doi.org/10.1111/evo.2012.66.issue-11

Turner, G. F. (2007). Adaptive radiation of cichlid fish. Current Biology, 17, R827-R831. https://doi.org/10.1016/j.cub.2007.07.026

Van Dooren, T. J. M., Van Goor, H. A., \& Van Putten, M. (2010). Handedness and asymmetry in scale-eating cichlids: Antisymmetries of different strength. Evolution, 64, 2159-2165.

Van Tienderen, P. H. (1997). Generalists, specialists, and the evolution of phenotypic plasticity in sympatric populations of distinct species. Evolution, 51, 1372-1380. https://doi.org/10.1111/j.1558-5646.1997.tb 01460.x 
Van Valen, L. (1965). Morphological variation and width of ecological niche. American Naturalist, 99, 377-390. https://doi.org/10.1086/ 282379

Verheyen, E., Salzburger, W., Snoeks, J., \& Meyer, A. (2003). Origin of the superflock of cichlid fishes from Lake Victoria, East Africa. Science, 300, 325-329. https://doi.org/10.1126/science.1080699

Via, S., \& Lande, R. (1985). Genotype-environment interaction and the evolution of phenotypic plasticity. Evolution, 39, 505-522. https://d oi.org/10.1111/j.1558-5646.1985.tb00391.x

Waddington, C. H. (1953). Genetic assimilation of an acquired character. Evolution, 7, 118-126. https://doi.org/10.1111/evo.1953.7.issue-2

Waddington, C. (1961). Genetic assimilation. Advances in Genetics, 10, 257-293.

Wagner, C. E., Keller, I., Wittwer, S., Selz, O. M., Mwaiko, S., Greuter, L., ... Seehausen, O. (2013). Genome-wide RAD sequence data provide unprecedented resolution of species boundaries and relationships in the Lake Victoria cichlid adaptive radiation. Molecular Ecology, 22, 787-798. https://doi.org/10.1111/mec.12023

Wang, Y., Azaïs, T., Robin, M., Vallée, A., Catania, C., Legriel, P., ... Nassif, N. (2012). The predominant role of collagen in the nucleation, growth, structure and orientation of bone apatite. Nature Materials, 11, 724-733. https://doi.org/10.1038/nmat3362

West-Eberhard, M. J. (1989). Phenotypic plasticity and the origins of diversity. Annual review of Ecology and Systematics, 20, 249-278. https://doi.org/10.1146/annurev.es.20.110189.001341

West-Eberhard, M. J. (2003). Developmental plasticity and evolution. New York, NY: Oxford University Press.

West-Eberhard, M. J. (2005). Developmental plasticity and the origin of species differences. Proceedings of the National Academy of Sciences of the United States of America, 102, 6543-6549. https://doi.org/10. 1073/pnas.0501844102

Wimberger, P. H. (1991). Plasticity of jaw and skull morphology in the neotropical cichlids Geophagus brasiliensis and G. steindachneri. Evolution, 45, 1545-1563. https://doi.org/10.1111/evo.1991.45.issue-7

Witte, F. (1981). Initial results of the ecological survey of the haplochromine cichlid rishes from the Mwanza Gulf of Lake Victoria (Tanzania) - Breeding patterns, trophic and species distribution With recommendations for commercial trawl-fishery. Netherlands Journal of Zoology, 31, 175-202.
Wund, M. A., Baker, J. A., Clancy, B., Golub, J. L., \& Fosterk, S. A. (2008). A test of the "Flexible stem" model of evolution: Ancestral plasticity, genetic accommodation, and morphological divergence in the threespine stickleback radiation. American Naturalist, 172, 449-462. https://doi.org/10.1086/590966

Wund, M. A., Valena, S., Wood, S., \& Baker, J. A. (2012). Ancestral plasticity and allometry in threespine stickleback reveal phenotypes associated with derived, freshwater ecotypes. Biological Journal of the Linnean Society, 105, 573-583. https://doi.org/10.1111/bij.2012.105.issue-3

Yamakoa, K. (1983). Feeding behaviour and dental morphology of algae scraping cichlids (Pisces: Teleostei) in Lake Tanganyika. African Study Monographs, 4, 77-89.

Yim, K. M., Brewer, M. S., Miller, C. T., \& Gillespie, R. G. (2014). Comparative transcriptomics of maturity-associated color change in Hawaiian spiders. Journal of Heredity, 105, 771-781. https://doi.org/10.1093/ jhered/esu043

Zhao, R., Davey, M., Hsu, Y.-C., Kaplanek, P., Tong, A., Parsons, A. B., ... Houry, W. A. (2005). Navigating the chaperone network: An integrative map of physical and genetic interactions mediated by the hsp90 chaperone. Cell, 120, 715-727. https://doi.org/10.1016/j.cell.2004. 12.024 